\title{
Compassion Fatigue, Secondary Traumatic Stress, and Vicarious Traumatization: a Qualitative Review and Research Agenda
}

\author{
Rachel S. Rauvola ${ }^{1}$ (D) Dulce M. Vega ${ }^{1} \cdot$ Kristi N. Lavigne $^{1}$
}

Received: 18 January 2019 /Revised: 18 July 2019 / Accepted: 22 July 2019 / Published online: 10 August 2019 (C) Springer Nature Switzerland AG 2019

\begin{abstract}
There has been growing research interest in what we term empathy-based stress, a process of traumatic stressor exposure, empathic experience, and adverse reactions among particular empathy-related professions, captured in the literatures on compassion fatigue, secondary traumatic stress, and vicarious traumatization in trauma-related lines of work. Although these three empathy-based strain constructs are highly related, each represents different components of similar strain responses. Unfortunately, extant reviews of the empathy-based stress literature are non-comprehensive and/or out of date. This qualitative review thus aims to synthesize and summarize the current literature on empathy-based stress at work and contribute to theoretical, methodological, and practical improvements in this area of research and practice. After introducing empathy-based strain constructs and their defining characteristics, we detail our review methodology and the primary theoretical and empirical themes derived through our review of the past decade of published literature. Then, we summarize conceptual, methodological, and analytical gaps in the empathy-based stress literature, helping to generate recommendations for the literature moving forward.
\end{abstract}

Keywords Compassion fatigue $\cdot$ Empathy $\cdot$ Secondary traumatic stress $\cdot$ Stress $\cdot$ Trauma exposure $\cdot$ Vicarious traumatization

Although the study of stress and wellbeing at work is not new, research on traumarelated stress at work is a relatively novel addition to occupational health studies. We

Electronic supplementary material The online version of this article (https://doi.org/10.1007/s41542-01900045-1) contains supplementary material, which is available to authorized users.

Rachel S. Rauvola

shelly.rauvola@slu.edu

1 Department of Psychology, Saint Louis University, Morrissey Hall 2753, St. Louis,

MO 63103, USA 
define "empathy-based" stress, comprised of various strain constructs including compassion fatigue, secondary traumatic stress, and vicarious traumatization, in parallel with existing work stress literature. More specifically, empathy-based stress is a process of trauma exposure (i.e., a stressor) combined with the experience of empathy (i.e., an individually- and contextually-driven affective reaction) that results in empathy-based strain, adverse occupational health reactions, and other work-relevant outcomes. Figure 1 provides a visual depiction of this empathy-based stress model. Until now, empathy-based strain constructs have been primarily considered and critiqued in industry- and vocation-specific circles rather than from a broader work and organizational psychology-informed perspective (e.g., Hernández García 2017; Kitchingman et al. 2017; Sinclair et al. 2017). Moreover, these investigations have been limited in scope compared to the wealth of occupations exposed to trauma (e.g., clinical psychologists, emergency first responders, counselors, veterinarians). A fragmented but rapidly growing literature has amassed since the origination of empathy-based constructs, and they are thus in need of summary, synthesis, and critical analysis.

Given the prevalence of trauma-related work and organizations' desire to better understand how to sustain and support workers across their careers (Kilpatrick et al. 2013; Truxillo et al. 2015), the goals of describing, synthesizing, and analyzing this literature through an occupational health lens are quite appropriate. Moreover, as our awareness of trauma exposures across professions grows, including the apparent prevalence of sexual harassment and assault in the workplace and its direct and indirect victims, integrating empathy-based stress with the occupational health literature is greatly needed (Buckner et al. 2014; Quick and McFadyen 2017). Accordingly, the present review is motivated by a desire to describe and analyze the current state of the empathybased stress literature while generating an occupational health agenda for future research and practice. To our knowledge, no previous reviews have attempted these goals, and most recent reviews are limited by their focus on a specific vocation (e.g., mental health professionals, Turgoose and Maddox 2017; healthcare workers, Sinclair et al. 2017), work department (e.g., intensive care units, van Mol et al. 2015), or an antecedent or outcome relationship with a particular empathy-based strain construct (e.g., compassion fatigue and attachment styles, West 2015; secondary traumatic stress and burnout,

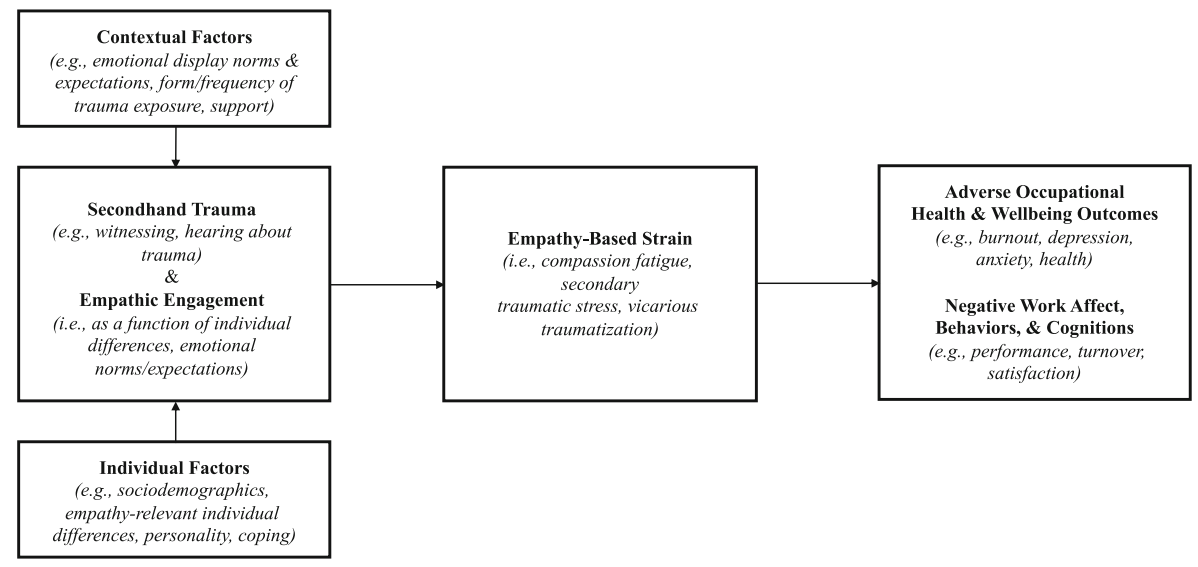

Fig. 1 Model of the empathy-based stress process 
Cieslak et al. 2014; secondary traumatic stress risk factors in therapy, Hensel et al. 2015). Additionally, more domain-general reviews and meta-analyses are outdated and noncomprehensive in their consideration of empathy-based stress (e.g., Baird and Kracen 2006, only consider vicarious traumatization and secondary traumatic stress publications from 1994 to 2003). Thus, the present review intends to provide an up-to-date summary and synthesis of the empathy-based stress literature and develop an analysis-informed agenda for occupational health research and practice moving forward.

In the following sections, we first define and describe "empathy-based stress", providing a new model of the empathy-based stress process informed by existing occupational health and work stress literature, as well as our core strain constructs of interest (i.e., compassion fatigue, secondary traumatic stress, vicarious traumatization). We then describe the methodology and scope of the review, followed by a discussion of the theoretical perspectives and antecedent/outcome relationships studied in the empathy-based stress literature. Importantly, we do not focus this section of the review on potential moderators or mediators studied in empathy-based stress models, as such variables are studied quite inconsistently in the literature and generally with insufficient theoretical and/or methodological rigor to generate valid conclusions. Finally, we provide a review of knowledge gaps identified from the literature, and we conclude with a research agenda for furthering the study of empathy-based stress.

\section{Defining "Empathy-Based Stress"}

For the purpose of our review, we adopt the broad term "empathy-based stress" to refer to a process that comprises the related strain constructs of compassion fatigue, secondary traumatic stress, and vicarious traumatization (see Table 1). Although there is not a clear precedent in the literature to refer to these constructs in a holistic sense (see Newell et al. 2016), and "empathy-based stress" is not used in the extant literature pertaining to this topic, we suggest that the three constructs of focus in our review are representative of the empathy-based stress process (albeit in different ways). We believe that empathy-based stress is an accurate portrayal of these constructs rather than vaguely referring to the constructs as the "risks" and "hazards" of certain professions, which implies that the constructs are conditions unique to "caring" professions (Newell and MacNeil 2010). In light of the strain definitions presented in the following sections and the work stress theory informing our integration efforts, we believe that "empathybased stress" is relevant to any individual in an occupational role exposed to secondhand trauma (i.e., distressing event, recurrent episodes, or enduring conditions) and who engages in some level and form of empathic response as a result (e.g., ranging from medical professionals and humanitarian aid workers, to researchers exposed to sensitive and stressful content and athletic coaches who witness severe injury).

As such, we define "empathy-based stress" as a stressor-strain-based process of trauma at work, wherein exposure to secondary or indirect trauma, combined with empathic experience, results in empathy-based strain and additional outcomes (i.e., other occupational health/strain outcomes; work affect, behaviors, and cognitions). As depicted in Fig. 1, this stress process is contingent not only upon both secondhand trauma exposure and empathic engagement, but is also impacted by individual and contextual (i.e., organizational and occupational) factors that may predispose 
Table 1 Construct definitions, symptoms, and related terminology

\begin{tabular}{|c|c|c|c|}
\hline Construct & Definition & Symptoms & $\begin{array}{l}\text { Alternate \& } \\
\text { related terms }\end{array}$ \\
\hline $\begin{array}{l}\text { Empathy-based } \\
\text { stress }\end{array}$ & $\begin{array}{l}\text { Experience of adverse } \\
\text { psychological and/or } \\
\text { physical reactions to } \\
\text { trauma exposure at work, } \\
\text { resulting from empathic } \\
\text { engagement following } \\
\text { trauma exposure }\end{array}$ & $\begin{array}{l}\text { Symptoms vary, } \\
\text { depending on the specific } \\
\text { manifestation of strain } \\
\text { (i.e., vicarious } \\
\text { traumatization, secondary } \\
\text { traumatic stress, } \\
\text { compassion fatigue, other } \\
\text { health outcomes) }\end{array}$ & $\begin{array}{l}\text { "Risks and hazards" of } \\
\text { caring work }\end{array}$ \\
\hline $\begin{array}{l}\text { Vicarious } \\
\text { traumatization }\end{array}$ & $\begin{array}{l}\text { Transformation of the } \\
\text { "inner experience" of } \\
\text { trauma-exposed } \\
\text { individuals (McCann and } \\
\text { Pearlman 1990; Pearlman } \\
\text { and Saakvitne 1995) }\end{array}$ & $\begin{array}{l}\text { Symptoms include } \\
\text { worldview shifts, } \\
\text { cognitive schema } \\
\text { disruptions }\end{array}$ & $\begin{array}{l}\text { Vicarious trauma; vicarious } \\
\text { posttraumatic growth, } \\
\text { vicarious resilience }\end{array}$ \\
\hline $\begin{array}{l}\text { Secondary } \\
\text { traumatic stress }\end{array}$ & $\begin{array}{l}\text { Stress reaction induced } \\
\text { following exposure to } \\
\text { traumatic material; PTSD } \\
\text { parallel (Figley 1995) }\end{array}$ & $\begin{array}{l}\text { Symptoms similar } \\
\text { to PTSD, but from } \\
\text { secondary exposure }\end{array}$ & $\begin{array}{l}\text { Secondary traumatization, } \\
\text { secondary traumatic } \\
\text { stress disorder }\end{array}$ \\
\hline $\begin{array}{l}\text { Compassion } \\
\text { fatigue }\end{array}$ & $\begin{array}{l}\text { Acute, affective } \\
\text { phenomenon } \\
\text { engendering high levels } \\
\text { of stress after trauma } \\
\text { exposure (Figley 1995) }\end{array}$ & $\begin{array}{l}\text { Symptoms parallel } \\
\text { original trauma victim's } \\
\text { (e.g., avoidance, } \\
\text { hyperarousal, numbing, } \\
\text { sleep disturbances) }\end{array}$ & $\begin{array}{l}\text { Compassion stress; } \\
\text { compassion satisfaction }\end{array}$ \\
\hline
\end{tabular}

individuals in particular environments to experience empathy-based stress (e.g., as a function of empathy-relevant individual differences, organizational or occupational norms to "connect" with patients through empathy). Our model of empathy-based stress is not intended to serve as a strict, unidirectional causal chain of events; instead, we present this model as a general outline of how empathy-based stress unfolds over time and as a product of multiple influences.

This model also helps illuminate the wide applicability of empathy-based stress, including its role outside of traditional "caring" professions, and its parallels with existing models of work stress. Our definition emphasizes the idea that anyone can be exposed to secondhand trauma, engage empathically, and experience adverse outcomes in the work context as a result. Still, certain individual and contextual factors may make the incidence of empathy-based stress more likely and/or potent (e.g., frequent vs. idiosyncratic trauma exposure, predisposition to empathize with others in the work context vs. remain distant). This is likely the reason that the study of empathybased stress currently lives in vocation-specific literatures. We believe that such division is misplaced and counterproductive. Instead of focusing on the incidence of compassion fatigue, secondary traumatic stress, and/or vicarious traumatization in a particular profession, the empathy-based stress literature is in need of cross-cutting discussions on the nature and boundary conditions of empathy-based stress at work more generally. Taking a broader, process-based approach is in keeping with extant theories of work stress in the occupational health literature (e.g., job demands- 
resources, Demerouti et al. 2001; conservation of resources, Hobfoll 1989) and parallels the recognition in recent years that burnout is not unique to "caring" or "people" work as it was once treated (e.g., Maslach 1982). These theories have been sparingly mentioned in the empathy-based stress literature (e.g., Dagan et al. 2016; Kim 2017), let alone integrated in the service of a more formal model, as in this review.

\section{Relevant Occupational Health Theory}

More specifically, theories of work stress such as job demands-resources (JD-R) and conservation of resources (COR) posit that strain (e.g., burnout, negative health outcomes) results from the interplay of context and available resources. From the COR perspective, resources are defined as "objects, personal characteristics, conditions or energies that are valued in their own right or that are valued because they act as conduits to the achievement or protection of valued resources" (Hobfoll 2001, p. 339), and strain outcomes result from resource loss, threat, or inadequate gains following resource investment. From the JD-R perspective, resources entail "physical, psychological, social, or organizational" job aspects that help individuals reach work goals, grow and develop, and/or reduce job demands (i.e., job aspects requiring effort/energy, linked to physical or mental costs) and subsequent strain (Demerouti et al. 2001, p. 501). Thus, strain is a result of demands and mismatched resources, wherein job demands independently as well as in the context of insufficient resources lead to exhaustion and other adverse outcomes. When these perspectives are applied to the empathy-based stress process, it is apparent that both individually and contextually derived empathy and trauma demands and resources determine the course of empathy-based stress in individuals. Figure 1 provides some examples of these demands and resources, although the precise impact of individual- and context-based demands (e.g., display norms, support) and resources (e.g., coping, empathy-related individual differences) on the empathy-based stress process is in need of a great deal more research. This work stress-based model also helps to illuminate the ways in which all three forms of empathybased strain, although different, share similar antecedents and consequences. Individual and contextual differences influence how empathy-based stress emerges and which empathybased strain is experienced. This occurs through such means as unique vocational and/or role stressors, stress- and strain-mitigating resources, organizational culture, and traits that characterize individuals who self-select into particular occupations. Still, we contend that empathy-based stress is an occupational health concern of relevance to anyone who is exposed to secondhand trauma at work and engages in some level of empathic response.

\section{Boundary Conditions of the Empathy-Based Stress Process}

Despite this wide applicability, there are notable boundary conditions that define the empathy-based stress process and its occupational health implications. Specifically, the nature of empathy responses and secondhand trauma bear elaboration.

First, empathy-based stress is not relevant to a) situations in which individuals experience only direct trauma (e.g., as the target or victim) rather than any secondhand trauma, or b) situations that only entail secondhand trauma exposure but lack a sufficient empathic engagement component. In the first case, wherein individuals are directly traumatized (e.g., as the victim of sexual assault on the job) but not exposed to any secondhand trauma, direct (e.g., posttraumatic stress disorder) rather than indirect, 
empathy-based strain outcomes would be expected. In the second case, wherein individuals are exposed to secondhand trauma but do not engage in an empathic response, empathy-based strain cannot result, as insufficient individual transformations or affect/symptom mirroring have occurred. Such cases could be attributed to two classes of sources. On the one hand a total lack of empathetic engagement could be the product of desensitization to trauma and/or individual differences in empathy, interpersonal reactivity, or personality. On the other hand, individuals may engage in a level of empathy insufficient for empathy-based strain. In prevailing occupational health terms, an individual may not experience a given secondhand trauma and its correspondent empathic engagement as a stressor. Without this perception, the strain response will not occur. For example, a hospice nurse may empathize with the bereaved family of a deceased patient with whom they did not work extensively, but this empathy response may not be at the same "level" (i.e., perceived as a stressor) as one felt for a patient's family with whom the nurse worked extensively.

Second, the nature of secondhand trauma, entailing a distressing event, recurrent episodes, or enduring conditions, bears clarification. While a distressing event refers to a one-time secondhand trauma exposure that is severe and acute in nature, enduring conditions of secondhand trauma are defined by chronic exposure and accumulation of strain over time. Episodic stressors fall in the middle, defined by the frequent and consistent experience of distressing events over time (Lazarus 2000). Importantly, each of these forms of stressors lead to different stress responses and forms of strain (e.g., Colligan and Higgins 2006). Although distinct from each other, we include the three forms of stressors in our definition given the variety of empathy-based strains possible across time and contexts. More specifically, an individual's work context (e.g., job, workplace, occupation) is quite important in defining the form of empathy-based strain that will be experienced, both as a function of empathic responses and secondhand trauma. Some jobs may (implicitly, in the form of shared norms, or explicitly, in job descriptions) require individuals to be exposed to trauma regularly and engage in empathic responses (e.g., pastors and chaplains, therapists, social workers). Other jobs may frequently involve secondhand trauma without as strong of an expectation of empathy (e.g., police officers, firefighters, insurance brokers) or infrequently to rarely involve trauma (e.g., accountants, chefs, salespeople). Thus, particular jobs, and their requirements and occupational standards, play a role in the form of secondhand trauma to which one is exposed (i.e., distressing event, recurrent episodes, enduring conditions), its subsequent empathic response, and the form of empathy-based strain that will result (see also van der Ploeg et al. 2003).

\section{Defining Empathy-Based Strain Constructs}

We next present definitions for the empathy-based strain constructs considered herein (see Table 1), as well as conceptual disagreements and related constructs in the literature. The core construct definitions we present often reference caregivers or specific "helping" vocations (i.e., human service professionals such as counselors, physicians, nurses). By using the broader term "empathy-based stress," which applies a more inclusive empathy-based view of each construct mentioned below, we contend and argue that these experiences are applicable outside of traditional "caring" professions and thus are a broadly relevant occupational health concern. 


\section{Vicarious Traumatization}

Based in constructivist self-development theory, vicarious traumatization is defined as the "transformation in the inner experience of the therapist that comes about as a result of empathic engagement with client's trauma material" (Pearlman and Saakvitne 1995, p. 31). This perspective implies that individuals construct their own reality, and that personal conceptions of reality and cognitive schemas are disrupted through exposure to others' (e.g., clients') traumatic reactions (McCann and Pearlman 1990). Vicarious traumatization is described as a more pervasive, longer-lasting shift in a caregiver's inner experience that results from disrupted beliefs regarding themselves, relationships, and the world, which distinguishes it from the more acute phenomena of secondary traumatic stress and compassion fatigue. For example, a high school teacher working in a disadvantaged neighborhood might experience vicarious traumatization through their experience over time with marginalized and "at-risk" youth (e.g., as a result of hearing stories of violence, extreme poverty, crime; witnessing or observing the physical signs of abuse). Through this experience, the teacher may come to view the world as a less just and lose a sense of meaningfulness or hope for their work and society. Although one might argue that using the term "vicarious trauma" parallels the nature of the other empathy-based strain construct terms considered in the present review, we chose to use "vicarious traumatization" to emphasize the transformative nature of the construct.

\section{Secondary Traumatic Stress}

Secondary traumatic stress describes the stress reaction induced in caregivers following exposure to clients' traumatic material. Specifically, Figley (1995) describes secondary traumatic stress as a class of "natural and consequential behaviors and emotions resulting from knowing about a traumatizing event experienced by a significant other (or client) and the stress resulting from helping or wanting to help a traumatized or suffering person" ( $\mathrm{p}$. 7). Over time, it is suggested that the caregiver develops some of the symptoms of posttraumatic stress disorder (PTSD), mirroring client symptoms. Clinically, this stress reaction refers to secondary traumatic stress disorder (e.g., Figley 1995; see also APA 2013 and "indirect exposure" categories included therein). As an example, a nurse who witnesses or hears about a gruesome, traumatic injury may experience secondary traumatic stress if their experience with traumatic material generates PTSD-like symptoms.

\section{Compassion Fatigue}

Compassion fatigue (occasionally "compassion stress"), is a term originally coined by Joinson (1992) in reference to burnout and nurses, and has been referred to as a more userfriendly substitute to secondary traumatic stress (see Figley 1993). Compassion fatigue is described as an acute, affective phenomenon that engenders high levels of stress for caregivers and in which caregivers' symptoms parallels those of the original trauma victim's (e.g., avoidance, hyperarousal, numbing, sleep disturbances; Figley 1995). In most operationalizations, compassion fatigue is viewed as a multi-dimensional construct composed of two dimensions, burnout and secondary traumatic stress (e.g., Stamm 2010). While secondary traumatic stress is acute, burnout is a gradual process of emotional exhaustion (Figley 1995). Researchers' conceptualizations of compassion fatigue often 
rely more heavily on one dimension (e.g., sudden secondary traumatic stress) than the other (e.g., cumulative burnout). Depending on which conceptualization of compassion fatigue is adopted (i.e., acute stress vs. progressive fatigue), compassion fatigue may manifest in parallel with the secondary traumatic stress example provided above (i.e., stress prompted immediately by a particular secondhand trauma exposure incident; a distressing event). It also may manifest more progressively (e.g., a police officer exposed to multiple secondhand traumas over time may become desensitized to trauma and experience empathy decrements; a product of recurrent episodes and/or enduring condition).

\section{Conceptual Disagreement in the Literature}

While the distinction between vicarious traumatization on the one hand and compassion fatigue and secondary traumatic stress on the other hand is fairly clear, the distinction between compassion fatigue and secondary traumatic stress is not. In some places, secondary traumatic stress is conceptualized as synonymous with compassion fatigue (e.g., Figley 1993), as a sub-component of compassion fatigue (e.g., Stamm 2010), or as a broader typology of stress that itself includes compassion fatigue (e.g., Brown et al. 2017). In a recent conceptual review of the empathy-based stress literature, Newell et al. (2016) present compassion fatigue as a divergent construct from secondary traumatic stress, suggesting secondary traumatic stress is a potential consequence of compassion fatigue. Moreover, some research describes compassion fatigue as cumulative and progressive rather than sudden and acute in nature (e.g., in line with "fatigue" moreso than traumatic stress; Cragun et al. 2016; Samson et al. 2016). Other research emphasizes the "compassion" component of the construct and its implications for empathic (dis)engagement and performance outcomes (e.g., Decker et al. 2015; Ravi et al. 2016).

\section{Related Constructs}

Over the years, the nomological network of compassion fatigue, secondary traumatic stress, and vicarious traumatization has expanded to include more positive or "growth" related constructs associated with trauma-related work. Specifically, vicarious resilience, posttraumatic growth, and compassion satisfaction refer to the generative aspects of "caring" work and acknowledge the presence of rewarding aspects of trauma-related vocations; as such, "positive" and "negative" outcomes are not mutually exclusive or orthogonal. While vicarious resilience and posttraumatic growth are seen as resulting from coping with (secondary) trauma and emerging resilient, compassion satisfaction results from the same empathic engagement that engenders compassion fatigue risk (see Cohen and Collens 2013; Samios et al. 2013). Empathic engagement is crucial to traumatic growth-related constructs, and some nomological ties have been made between the empathy-based stress literature and the emotional labor (e.g., through empathic concern; Latimer et al. 2017; Silver et al. 2018) and emotion regulation literatures (e.g., Mairean 2016a).

Outside of the direct purview of the empathy-based stress literature, but still related, are more traditional occupational health and stress constructs. Broad categories of stress such as "vocational stress" (e.g., Baranik et al. 2018) or experiences such as "spillover" of affect from work to home (e.g., Sonnentag and Binnewies 2013) may include empathy-based stress phenomena but do not possess the same level or combination of trauma exposure and empathic engagement. Perhaps the best-known associated construct 
is burnout, which coincidentally possesses a similar history to empathy-based strain constructs (and, as mentioned earlier, is considered by many to be a component of compassion fatigue). Specifically, burnout originated as a vaguely defined construct applicable to human service professionals. Through empirical investigation and theoretical expansion, however, it gained specificity (i.e., dimensional structure) and expanded beyond “caring” professions (Maslach et al. 2001). Burnout has been defined as a progressive-onset condition comprised of three dimensions: emotional exhaustion, depersonalization, and personal accomplishment (Maslach 1998). These dimensions entail emotional fatigue, disengagement and distancing behaviors, and a reduced sense of fulfillment. Parallels between burnout and empathy-based strain include experiencing (secondary traumatic) stress symptoms (e.g., detachment, numbing), (compassion) fatigue, and implied (compassion) satisfaction decrements. However, the precipitating factors for empathybased strain (trauma exposure, empathic engagement) as well as the timing of their onset (variable, ranging from cumulative to sudden) are clear points of divergence between the two constructs. As will be discussed later, it may be that the distinction between the two is not as important as their joint consideration in a model of empathy-based stress.

\section{Methodology for the Present Review}

A detailed coding guide was developed by the first author to direct the review process (i.e., verify that proper labeling and coding of information pertinent to the review was documented; full guide and example coded articles available in Supplementary material. Specifically, for articles that met the inclusion criteria discussed next, we coded information about the study: its general theoretical framework (i.e., main perspectives cited in introducing the study, perspective on the construct(s) of interest), the construct definition(s) provided and the specific core constructs considered (i.e., compassion fatigue, secondary traumatic stress, vicarious traumatization), the methodology used (e.g., cross-sectional survey, semi-structured interviews), the predictor and outcome variables measured in the study (if quantitative), and a general summary of the results. These coded components were then translated directly into sections of the present review, as described below.

\section{Literature Search}

To gather relevant literature, the three authors conducted systematic searches between September 2017 and May 2018 through a number of academic databases (i.e., Emerald, EBSCOHost/ERIC, JSTOR, PsycINFO, ScienceDirect, and Web of Science) to identify relevant articles for inclusion. To search each of these databases, we used the terms "compassion fatigue", "secondary traumatic stress", "vicarious traumatization", "vicarious trauma", and "compassion stress" to identify papers. Prior to the application of any exclusion criteria, we yielded a total of 4,091 search results. We only considered for inclusion those qualitative and quantitative studies that were a) empirical, b) published in peer-reviewed journals (i.e., book chapters, unpublished master's theses and dissertations were excluded) between 2007 and 2018, and c) measured and/or analyzed at least one of our core empathy-based strain constructs (i.e., compassion fatigue, secondary traumatic stress, vicarious traumatization) with relation to paid or unpaid employees (e.g., volunteers, students completing professional training). Thus, all studies involved the assessment of one 
or more of our constructs in samples of workers subject to empathy-related stressors in their occupation. As many of these terms were only introduced within the past 25 years, drawing from the past decade of literature allowed us to focus specifically on established perspectives and recent trends in the study of empathy-based stress at work. After applying our exclusion criteria, we concluded with a total of 724 papers to consult for the review; the article counts drawn from each database are available in our Supplementary material. In addition to included papers, other non-empirical qualitative papers (e.g., qualitative reviews for specific vocations) were consulted to help identify broader themes in the empathybased stress literature, and original scale papers pre-dating 2007 were referenced in crafting our methodological critiques as they are still the most widely used measures.

\section{Division of Labor and Reliability}

To assess and improve coding reliability, the three authors independently completed an index for 12 articles and then compared their coded results; any disagreement was discussed until agreement was reached so that all indexing was done in a reliable and consistent manner. The reliability assessment was conducted in two separate phases to ensure sufficient and successive agreement had been reached. Sufficiency of agreement was determined based upon a qualitative appraisal of consistency of coded content (e.g., the same definitions and constructs were noted, the same methodology was identified, the operationalization of each construct was input satisfactorily, as well as the outcome variables of interests). The database searches and indexing were divided among the authors according to total item yields such that the first author was responsible for PsycINFO, the second author was responsible for Emerald, EBSCOHost/ERIC, JSTOR, and ScienceDirect, and the third author was responsible for Web of Science. Throughout the indexing process, the authors identified common themes, definitions, measures, and knowledge gaps that were distilled into the review.

\section{Writing the Review}

The "distilling" process used to craft this review was based directly upon the items coded for each included paper, primarily in terms of the incidence and apparent consequences of certain approaches, perspectives, or other paper components. Cited works and theories used in papers' introductions formed the basis for the three main theoretical frameworks described herein, and construct definitions were used in developing our own empathybased stress definition and model, defining each empathy-based strain construct, and critiquing the existing literature (e.g., areas of ambiguity or treatment of constructs interchangeably). Methodological information and results (i.e., type of study, operationalization, predictor and outcome variables considered, primary results) informed our theoretical frameworks as well as our description of and recommendations for the study of empathy-based stress. Any other comments were leveraged to support particular critiques (e.g., of analytic methods) and future research directions. As the coding process progressed, certain patterns (e.g., with respect to themes, gaps) became apparent, which were noted in the comments section and discussed in group meetings. The authors compiled a joint database with all coded information, which was then used for outlining the review (i.e., to select salient and consistent strengths or issues in the literature) and then identifying exemplar papers for citation while writing the review. 


\section{Scope of the Review}

Although this is not a meta-analytic review, our approach was intended to help guard against "fugitive literature" (e.g., Rosenthal 1995) or articles that might otherwise be missed or ignored (e.g., due to being published in minor journals) but which hold equivalent weight in the review process. By using multiple databases and comprehensive keyword searches, we tried to capture as many relevant papers as possible. We cast our "net" quite wide in initial searching, thereby mitigating the risk of overlooking a paper that employed a novel term for a construct that otherwise fit within our review. It is important to note, too, that many of the papers included in the present review mentioned two if not all three constructs at least somewhere in their text or reference lists (in addition to any alternative terms for the same constructs). Thus, the likelihood of missing a relevant paper from the databases surveyed is relatively small. Additionally, when developing our plan for the review, we extensively searched the literature to determine a representative and comprehensive list of empathy-based strain constructs to include. Compassion fatigue, secondary traumatic stress, and vicarious traumatization were the most common terms in the literature and appeared to be the prevailing vocabulary for referring to empathy-based strain constructs. Thus, they were the natural choice for our comprehensive review of empathy-based stress. Finally, we did not exclude any papers based upon the journal in which they were published regardless of impact factor or "quality". A full list of included papers is available in our Supplementary material as well.

As is hopefully evident, the empathy-based stress literature is quite extensive. Thus, we strive to be as comprehensive as possible while still strategically focusing on key theory and approaches to the study of empathy-based strain constructs. Specific coverage of included papers is intended to aid in describing and synthesizing the current literature and identifying knowledge gaps in the past decade of empathy-based stress research through critical analysis. As such, not all papers included based on our review criteria will be directly discussed or cited herein; rather, those works that stand to contribute to substantive points and synthesis are of focus and priority. Still, our discussion is rooted in the full scope of our search and is intended to be representative of the current state of the literature. To this point, the following section will showcase the primary theoretical approaches taken with the study of empathy-based strain constructs and the general networks and frameworks in which the constructs are studied (e.g., where and how the constructs are modeled with respect to antecedents and outcomes).

\section{Theoretical Perspectives on Empathy-Based Stress}

In reviewing the literature, three primary theoretical approaches to the discussion and study of empathy-based strain constructs are apparent. We adopt the following terms for each "theory" in turn: an experiential, a resiliency, and a fatigue etiological perspective (see Table 2).

\section{Experiential Perspective}

The "experiential" approach to the study of empathy-based stress is perhaps the most commonly mentioned in the literature, and it focuses on the symptoms requisite to the 
Table 2 Theoretical frameworks in the empathy-based stress literature

\begin{tabular}{|c|c|c|c|}
\hline $\begin{array}{l}\text { Theoretical } \\
\text { framework }\end{array}$ & Defining characteristics & Origins & Applications \\
\hline Experiential & $\begin{array}{l}\text { Focus on symptoms } \\
\text { of trauma exposure }\end{array}$ & $\begin{array}{l}\text { Clinical approach: } \\
\text { empathy-based } \\
\text { stress as PTSD }\end{array}$ & $\begin{array}{l}\text { Primarily manifests in } \\
\text { measurement of } \\
\text { empathy-based stress }\end{array}$ \\
\hline Resiliency & $\begin{array}{l}\text { Focus on individual and } \\
\text { organizational factors that } \\
\text { predispose employees to } \\
\text { suffer (or grow) from } \\
\text { empathy-based stress } \\
\text { symptoms; also factors that } \\
\text { with coping and adaptation }\end{array}$ & $\begin{array}{l}\text { Epidemiological approach: } \\
\text { incidence, treatment, and } \\
\text { prevention of } \\
\text { empathy-based stress }\end{array}$ & $\begin{array}{l}\text { Most common study } \\
\text { design, with various } \\
\text { predictors (e.g., work } \\
\text { hours, personality) } \\
\text { used to explain } \\
\text { occurrence of } \\
\text { empathy-based stress }\end{array}$ \\
\hline $\begin{array}{l}\text { Fatigue } \\
\text { etiological }\end{array}$ & $\begin{array}{l}\text { Focus on mechanisms by which } \\
\text { empathy-based stress arises } \\
\text { and can be worsened }\end{array}$ & $\begin{array}{l}\text { Process approach: } \\
\text { trajectories of } \\
\text { empathy-based stress }\end{array}$ & $\begin{array}{l}\text { Referenced very rarely in } \\
\text { literature and not tested }\end{array}$ \\
\hline
\end{tabular}

experience of compassion fatigue, secondary traumatic stress, and vicarious traumatization. Specifically, the experiential approach conceptualizes experiential, environmental factors within trauma-related work contexts as producing symptoms akin to, or even commensurate with, PTSD in workers. While many papers view empathy-based constructs as distinct from PTSD, some research treats them as synonymous (e.g., Ewer et al. 2015; Turliuc et al. 2015). In both cases, the experiential approach forms much of the foundation for the operationalization of empathy-based stress in the literature. This includes utilizing Diagnostic Statistical Manual V (DSM-V) criteria (e.g., Secondary Traumatic Stress Scale, Bride et al. 2004), making use of PTSD checklists to assess empathy-based strain constructs (e.g., Akinsulure-Smith et al. 2012; Dworkin et al. 2016), or using PTSD treatments (e.g., eye movement desensitization and reprocessing; Keenan and Royle 2007) in attempt to ameliorate their symptoms. Although it bears operational utility, the experiential perspective does not explain why or how individuals respond to their environment in ways that induce empathy-based strain. The other two primary theoretical approaches in the literature, the resiliency and fatigue etiological perspectives, help to fill this gap in slightly different ways.

\section{Resiliency Perspective}

The "resiliency" perspective is used in studying the factors, both individual and organizational, that predispose employees to suffer (or grow) from empathy-based stress symptoms. In addition, it considers the factors that help employees cope with, and adapt to, secondhand traumatic work stressors. The scope of such factors is wide-ranging, including personal risk factors (e.g., personal trauma history, internalization tendencies) and protective factors (e.g., personality traits, self-care practices), as well as work-related and environmental risk (e.g., lack of training, caseload/work hour practices) and protective factors (e.g., supervision, team debriefing). Many papers using the resiliency perspective mention "resilienc(e/y)" directly (e.g., Hiles Howard et al. 2015) or through their focus on various empathy-based growth constructs (e.g., compassion satisfaction; Samios et al. 2013); if neither of these approaches is taken, at the very minimum, studies are grounded in the investigation of person- and 
context-based protections and vulnerabilities for empathy-based stress. The resiliency perspective can also be considered as an "epidemiological" approach to studying the incidence and experience of empathy-based stresses (e.g., Craig and Sprang 2010; Molnar et al. 2017). Mixed and unanticipated results across the literature likely prompted the resiliency approach. For example, low symptom or risk levels are found in some populations where high levels of empathy-based strain are expected, and there is often a lack of support for theoretically consistent relationships, such as between exposure to secondhand trauma at work and empathy-based strain (e.g., caseload, trauma exposure "severity"; see Hensel et al.'s 2015, secondary traumatic stress meta-analysis; Hatcher and Noakes 2010). Interestingly, rather than these factors being studied as moderators or mediators in the literature, they are primarily treated as antecedent, concurrent, or (more rarely) outcome variables. Overall, however, this approach contributes to the conceptualization of the empathy-based stress process in the present review by presenting particular individual and contextual demands and resources that make the experience of empathybased stressors, strains, and associated outcomes more or less likely to occur.

\section{Fatigue Etiological Perspective}

The "fatigue etiological" perspective, based in work by Figley (2002), is an extension of the resiliency approach in that it describes the process of empathy-based stress responses. Rather than focusing on the factors that precipitate individuals' empathy-based stress responses, the fatigue etiological perspective seeks to explain the trajectory of stress responses. Specifically, the fatigue etiological approach (also referred to by Figley as the Compassion Stress and Fatigue Model; see Figley 1995) outlines the empathic mechanisms by which compassion fatigue (and, by extension, secondary traumatic stress and vicarious traumatization) arise (e.g., empathic concern, ability) and can be worsened (e.g., client exposure, job demands) or mitigated (e.g., disengagement, self-care, sense of achievement) over time. More broadly, it specifies a fundamental conflict for those in trauma-related and/ or "caring" professions: the way that empathy can enhance care outcomes for clients while simultaneously increasing individuals' vulnerability to empathy-based stress.

Unfortunately, it is only the minority of the studies examined for the present review that mention (e.g., Badger et al. 2008; Choi 2017), let alone formally test, propositions of the model, although the overwhelming majority reference Figley's (1995, 2002) original fatigue etiological work. Of the three theoretical approaches in the literature, the fatigue etiological approach seems to be the most overlooked, and yet most critical, to understanding empathy-based stress experiences and their work-relevant outcomes. Using process models such as the fatigue etiological perspective or the more general empathy-based stress model presented herein, we can investigate how empathy-based strain phenomena emerge, progress, and subside (e.g., either through active intervention or natural decline). Without knowledge about empathy-based stress processes, efforts to prevent the negative outcomes of empathy-based stress, and even the timing chosen for study designs, will miss potentially key etiological information. It is worth noting that vicarious traumatization's own "etiological model" (i.e., constructivist self-development theory; McCann and Pearlman 1990) emphasizes individuals' cognitive schemas and shifted interpretations of the world and reality following traumatic events. However, constructivist self-development theory originated to explain primary trauma responses and does not lend itself directly (or operationally) to work behavior and outcomes. 
Although most studies use the experiential, resiliency, and fatigue etiological perspectives in a piecemeal fashion, the perspectives appear to be more complementary than their utilization would suggest. In one of the more integrative approaches found in the present review, Galek et al. (2011) ground their study in the idea of compassion fatigue, secondary traumatic stress, and vicarious traumatization as "occupational stress syndromes" characterized by interactions between "individual and institutional characteristics in which 'the self' combines with 'the system"' (Galek et al. 2011, p. 635). Each of the empathy-based stress perspectives (i.e., experiential, resiliency, fatigue etiological) is apparent in their conceptualization as well, including a focus on stress responses and symptoms, the interplay of individual and contextual protective and risk factors, and the need to study empathy-based (stress) processes and how these processes unfold over time.

\section{Antecedents and Outcomes of Empathy-Based Stress}

Just as there is a mix of theoretical perspectives on empathy-based stress, there is a great quantity of mixed findings in the empathy-based stress literature as well. Past critiques of the literature (e.g., Craig and Sprang 2010; Sabin-Farrell and Turpin 2003) discuss the mismatch between quantitative studies, which generate inconsistent evidence for the incidence of empathy-based strain (let alone theoretically relevant construct relationships), and qualitative studies, which point unequivocally toward the existence of empathy-based stress experiences in trauma-related work. Constructs such as age (e.g., as a proxy for gained life and work experience), trauma exposure at work (e.g., contact with traumatized individuals, work hours), and personal trauma experience (e.g., past history of trauma exposure, abuse) manifest null or mixed results depending on their context, operationalization, and other possible factors (see Sinclair et al. 2017; Turgoose and Maddox 2017 for recent reviews). Therefore, in this section, we focus on presenting the types of antecedent and outcome variables that are typically studied in the empathy-based stress literature, rather than the magnitude of observed relationships; given that we include qualitative studies in this section, this is appropriate. Finally, it is important to note that the placement of certain variables as "antecedents" and "outcomes" varies in the quantitative empathy-based stress literature, depending on the perspective leveraged in a given study. We first discuss occupational health antecedents and outcomes, primarily studied through the resiliency framework, and then provide a review of more traditional work affect, behavior, and cognition antecedents and outcomes. Again, we note that moderators and mediators are not covered herein, as their treatment and investigation in the literature is inconsistent.

\section{Occupational Health \& Wellbeing}

Studies using the "resiliency" framework are most common in the empathy-based stress literature, and they often focus on constructs, in addition to empathy-based stress, that are relevant to occupational health and wellbeing. In quantitative resiliency studies, empathybased strain constructs are generally linked to other occupational strain constructs (e.g., burnout, health outcomes). A "typical" study of empathy-based stress uses personal and professional characteristics (i.e., individual/institutional factors from the resiliency framework) to predict psychological wellbeing outcomes (e.g., psychological distress, depression, anxiety, perceived stress; Harker et al. 2016; Kindermann et al. 2017; Rossi et al. 2012). 
Physiological wellbeing outcomes are considered occasionally as well (e.g., heart rate, blood pressure, physical quality of life, activity, health status; Butler et al. 2017; Haik et al. 2017; Riley et al. 2017). Often, however, empathy-based strain constructs are the sole outcomes of interest (e.g., Craun and Bourke 2014; Thomas and Otis 2010; Williams et al. 2012). In those studies taking a resiliency perspective, relevant factors such as coping strategy use, self-efficacy, "self-compassion", individual differences in empathy (e.g., empathic ability/ concern, perspective taking, interpersonal reactivity, emotional separation), trait mindfulness, and empathy/trauma-based growth constructs are often measured as well (e.g., Dutton et al. 2017; Levy et al. 2011; Manning-Jones et al. 2016; Slatyer et al. 2018; Yip et al. 2017).

"Negative" (i.e., maladaptive) coping mechanisms, such as denial, substance (ab)use, social isolation, or overeating, are frequently included in the literature (Craun et al. 2014; Jarrad et al. 2018; Ting et al. 2008) in addition to "positive" (i.e., emotion-focused, problem-focused) coping mechanisms, such as physical activity, mindfulness practice, humor, spirituality, and support seeking (e.g., Craun et al. 2014; Thompson et al. 2014; Whitebird et al. 2013). Notably, different forms of humor have been linked to different stress processes and strain outcomes (Craun and Bourke 2014), and multiple forms of support seeking have been considered, including formal help outside of the work context (e.g., mental health care; Bearse et al. 2013).

\section{Qualitative Research}

Qualitative studies follow similar patterns, trying to elicit information about individuals' experience of (secondary) trauma, the incidence of positive and negative wellbeing outcomes, and the factors associated with individuals' experience (e.g., Jakimowicz et al. 2018; Kita 2015; Pack 2014). Interestingly, vicarious traumatization and its contributing factors seem to be more frequently investigated using qualitative methods (e.g., semi-structured interviews, focus groups, case studies) than are secondary traumatic stress or compassion fatigue. The greater use of qualitative methods may be a product of the selfconstructivist development theory underlying vicarious traumatization, as this theory implies intraindividual variability in worldview shifts (i.e., depending on initial worldviews and beliefs). More research regarding the relative benefits and drawbacks of qualitative approaches to studying different forms of empathy-based strain is needed.

\section{Infrequently Studied Variables}

Additional individual and contextual variables of relevance to this review's model of empathy-based stress are less frequently considered in the literature. Emotional labor practices (e.g., individual deep or surface acting) and expectations (e.g., organizational or role display norms), for example, are only tangentially discussed (e.g., Goldblatt 2009; Van Sant and Patterson 2013) rather than measured in much of the literature (cf. Mizuno et al. 2013). The same can be said of personality traits relevant to empathy-based stress, such as agreeableness, extraversion, and neuroticism, which are studied only sparingly (e.g., LaFauci Schutt and Marotta 2011; Mairean 2016b; O'Mahony et al. 2018). Organizational attributes or composite climate measures are employed but are inconsistent in the attributes measured. Sawatzky and Enns (2012), for example, considered scheduling, collaboration, management, staffing, resources, professional practice, and competence within their organizational climate measure, while Kaewpan et al. (2017) considered structure, 
responsibility, rewards, work risks, warmth, support, performance standards, conflict, and identity as relevant components of climate (Kaewpan et al. 2017). Yet others focus on shared power (i.e., shared decision-making, respect for diversity) as an organizational structure-based resource for secondhand trauma-exposed employees (Slattery and Goodman 2009), or on person-work-life fit in the areas of workload, values, community, fairness, rewards, and control (Ray et al. 2013). Thus, the types of organizational attributes considered, as well as their operationalization (e.g., in terms of description vs. congruence approaches), varies.

\section{Work Affect, Behaviors, and Cognitions}

Several studies include more traditional work outcomes in their models, such as continuance or turnover intentions (e.g., Austin et al. 2017; Borntrager et al. 2012; Bride and Kintzle 2011; Graham et al. 2016; Locatelli and LaVela 2015; Sawatzky and Enns 2012; Sung et al. 2012), work engagement (Samson et al. 2016; Setti and Argentero 2014; Silver et al. 2018), and job satisfaction (e.g., Bellicoso et al. 2017; Bourke and Craun 2014; Kim et al. 2017; Li et al. 2014; Meyer et al. 2015; Muliira and Ssendikadiwa 2016; Potter et al. 2013; Roney and Acri 2018; Tabaj et al. 2015; Yeung et al. 2017). By and large, these studies are correlational in nature, although we present work affect, behaviors, and cognitions as outcomes in our model. This is in line with prevailing conceptualizations in the work stress literature (e.g., Bakker et al. 2004) but does not diminish the potential for reciprocal linkages over time.

Interestingly, objective or subjective performance indicators seem to only be used within experimental studies investigating trauma processing (i.e., as a proxy for the effects of secondary traumatic stress symptoms; Ivcic and Motta 2017) and "empathic accuracy" (i.e., inferences about videotaped individuals' thoughts and feelings; O'Brien and Haaga 2015) rather than in investigating correspondence between required and actual performance levels (e.g., through patient care outcomes, supervisor-rated job performance). Some job behaviors (e.g., therapy techniques, Craig and Sprang 2010; Zeleskov-Doric et al. 2012; prescription administration, use of restraints, Hidalgo et al. 2016) are measured, but only infrequently. Additionally, job behaviors are generally oriented to be resilience or risk factors, rather than indicators of performance (cf. Kulkarni et al. 2013). Finally, factors external to work with bearing on occupational decision-making (e.g., work-family spillover, Finzi-Dottan and Kormosh 2018; interpersonal functioning, intimacy, relationship satisfaction, RobinsonKeilig 2014) are sparingly studied. Furthermore, they are mainly studied as antecedent resilience or risk factors rather than as potential outcomes of (or products of dynamic interplay with) empathy-based stress in trauma-related work.

\section{Knowledge Gaps in the Study of Empathy-Based Stress}

Although the empathy-based stress literature has made great progress, critical knowledge gaps remain. In the following section, we will identify the knowledge gaps apparent from our review of the literature as well as offer preliminary recommendations for addressing these gaps. The identified knowledge gaps, framed as questions below, include the definition and measurement of empathy-based strain constructs as well as the research designs and analytic techniques employed in studies of empathy-based 
Table 3 Knowledge gaps and recommendations for empathy-based stress research

\begin{tabular}{|c|c|c|c|}
\hline Knowledge gap & Key questions & Current literature & Recommendations \\
\hline $\begin{array}{l}\text { Conceptual } \\
\text { properties }\end{array}$ & $\begin{array}{l}\text { How are empathy-based } \\
\text { strain constructs distinct } \\
\text { from one another? } \\
\text { How do they relate to } \\
\text { burnout? }\end{array}$ & $\begin{array}{l}\text { Competing explanations } \\
\text { about distinctions } \\
\text { Evidence suggests } \\
\text { high overlap }\end{array}$ & $\begin{array}{l}\text { Consider burnout as additional } \\
\text { outcome of general } \\
\text { empathy-based } \\
\text { stressor-strain proces } \\
\text { Conduct thorough } \\
\text { comparative studies }\end{array}$ \\
\hline $\begin{array}{l}\text { Contextual } \\
\text { application }\end{array}$ & $\begin{array}{l}\text { To which contexts and } \\
\text { professions is } \\
\text { empathy-based stress } \\
\text { applicable? }\end{array}$ & $\begin{array}{l}\text { Wide range of samples } \\
\text { represented without } \\
\text { differentiation or core } \\
\text { attributes defined }\end{array}$ & $\begin{array}{l}\text { Provide transparent and } \\
\text { complete definitions of } \\
\text { compassion, trauma, } \\
\text { empathy, etc. } \\
\text { Systematically address person } \\
\text { and context factors } \\
\text { Explore "new" work } \\
\text { contexts (telework, } \\
\text { humanitarian aid workers) }\end{array}$ \\
\hline $\begin{array}{l}\text { Qualitative } \\
\text { Contributions }\end{array}$ & $\begin{array}{l}\text { How does qualitative } \\
\text { research contribute to } \\
\text { our understanding of } \\
\text { empathy-based stress? }\end{array}$ & $\begin{array}{l}\text { Lack of replication } \\
\text { across studies } \\
\text { Small sample sizes }\end{array}$ & $\begin{array}{l}\text { Employ more rigorous } \\
\text { qualitative methods } \\
\text { Utilize mixed-methods } \\
\text { to triangulate findings }\end{array}$ \\
\hline Temporality & $\begin{array}{l}\text { What is the temporal } \\
\text { nature } \\
\text { of empathy-based stress? } \\
\text { How should we measure } \\
\text { empathy-based stress? } \\
\text { How should we } \\
\text { design studies of } \\
\text { empathy-based stress? } \\
\text { How should we analyze } \\
\text { empathy-based } \\
\text { stress data? }\end{array}$ & $\begin{array}{l}\text { Psychometric issues and } \\
\text { validation } \\
\text { shortcomings } \\
\text { Issues with intervention } \\
\text { designs, time lags } \\
\text { Use of cut-off/categorical } \\
\text { data approaches, } \\
\text { inductive approaches } \\
\text { to analysis }\end{array}$ & $\begin{array}{l}\text { Conduct validation studies with } \\
\text { substantive variables, large } \\
\text { samples, consideration of } \\
\text { common method variance } \\
\text { Use control groups, multiple } \\
\text { time points, justified time lag } \\
\text { choices, multilevel analyses } \\
\text { Treat data as continuous, test } \\
\text { specific hypotheses and } \\
\text { consider effect sizes and } \\
\text { confidence intervals }\end{array}$ \\
\hline
\end{tabular}

stress (see Table 3). These issues are prime areas for further exploration and improvement for the empathy-based stress literature, and thus feed directly into our proposed occupational health research agenda.

\section{How Are Empathy-Based Strain Constructs Distinct from One Another, and How Do they Relate to Burnout?}

The most fundamental and noticeable issue in the empathy-based stress literature is the substantial variability in how studies use and define empathy-based strain constructs. Construct ambiguity not only creates problems with integrating findings across the literature, but it also throws into question the distinctness of empathy-based strain constructs from one another as well as from burnout (i.e., the "jangle" fallacy; Kelley 1927).

To this latter point, many studies suggest that compassion fatigue, secondary traumatic stress, and vicarious traumatization are distinct from burnout (e.g., O'Brien and Haaga 2015; Slatten et al. 2011; Yan and Beder 2013), while others contend that burnout is a core component of empathy-based strain constructs (e.g., compassion fatigue; see Stamm's 2010, conceptualization as an example). Yet other studies suggest that empathy-based 
strain constructs are their own distinct, trauma-induced manifestations of burnout (e.g., Linnerooth et al. 2011; Orkibi 2016), with some even opting to measure these constructs with burnout inventories (e.g., Leake et al. 2017). Based on the model adopted in the present review, and the occupational health theory used to guide our definition of empathy-based stress, we contend that burnout must be neither synonymous with nor distinct from processes of compassion fatigue, secondary traumatic stress, and vicarious traumatization. Instead, burnout is an additional outcome of the general empathy-based stressor-strain process, wherein trauma exposure and empathic engagement (stressors) prompt empathy-based strain and other adverse outcomes in turn (e.g., burnout, health decrements). Burnout in particular may result as an additional strain outcome when individuals are repeatedly exposed to trauma and/or trauma/empathy demands that deplete an individual's energetic resources over time.

Quantitative evidence would suggest that empathy-based strain constructs are highly related to one another as well as to burnout. Few studies report intercorrelations or shared variance parameters for empathy-based strain constructs and burnout (e.g., measured with the Maslach Burnout Inventory; Maslach et al. 1996), but those that do report them support a good deal of overlap (e.g., $r=.64$ in Birinci and Erden 2016; $r=.59$ Ray et al. 2013; see also Setti et al. 2016). Some studies have attempted to parse burnout and empathy-based stress relationships temporally (e.g., Shoji et al. 2015), conceptually (e.g., Jenkins et al. 2011), or in practical settings (e.g., Newell and MacNeil 2011). Such efforts would aid in understanding the progression and dynamic interplay between stressors, strains, and outcomes in the empathy-based stress literature. We would recommend that additional comparative studies be undertaken to further explore the relationships between these constructs (e.g., as in Meadors et al. 2009), with particular focus on which outcomes are "more" or "less" predictable by particular strains, and which strains are best predicted by which types of stressors (e.g., forms of secondhand trauma, form of empathy). For instance, it may be that the conceptualization of burnout as a component of compassion fatigue is attributable to a stronger link between compassion fatigue (as compared to other empathy-based strain constructs) and burnout.

\section{To which Contexts and Professions Is Empathy-Based Stress Applicable?}

The distinctness of empathy-based strain constructs is unclear as well as the constructs' use in varying professions. In our review of the literature, samples ranging from more traditional caregiving professions such as social workers, therapists, chaplains, and nurses, to more unexpected secondhand trauma-exposed workers such as actors (Robb et al. 2016), qualitative research transcriptionists (Kiyimba and O'Reilly 2016), criminal lawyers (Vrklevsiki and Franklin 2008), and sports coaches (Day et al. 2013), were represented. Moreover, individuals who were exposed to (secondary) trauma through narratives were included, in addition to individuals exposed to (primary) trauma in violent work contexts (e.g., in "enforcement" professions; Kita 2015) and in nonhuman contexts (e.g., animal care; Rank et al. 2009). Individuals exposed to "shared trauma" in warzones (e.g., Lev-Wiesel et al. 2009) and disaster contexts (e.g., Bauwens and Tosone 2014) were represented as well.

Little is done to differentiate between contextual or professional categories (cf. Tosone et al. 2011). Moreover, the definitions of "trauma", "compassion", and 
"empathy" (as well as its distinction from sympathy; van der Watch et al. 2013) are assumed and unspecified in many studies but have relevance to the breadth and applicability of empathy-based strain constructs (Fernando III and Consedine 2017; Ledoux 2015). Unfortunately, the exact nature of these constructs may differ substantively across occupational applications. For instance, "compassion" may entail intraand/or interpersonal reactions depending on the social context of trauma in particular industries and roles (e.g., trauma through active interaction vs. passive witnessing, exposure to human vs. non-human trauma victims, acute vs. repeated exposure). Ensuring that definitions are provided transparently and completely, and that they "fit" within the parameters of empathy-based stress (i.e., trauma as secondhand exposure to content and/or interactions, combined with empathic engagement) will be a good start for the literature.

Additionally, new work contexts raise questions about empathy-based stress in "alternative" occupational settings. For example, technological advancements may provide increased risk for empathy-based stress, as well as increased opportunities for intervention. More occupational health research in recent years has been dedicated to studying the benefits and adverse effects of "telework" (e.g., Hartig et al. 2007; Nayani et al. 2017; Nijp et al. 2016). Although the increased flexibility and connectivity afforded by technology can be advantageous for workers, the infiltration of "work life" into "non-work life" and the inability to "unplug" may pose threats as well, particularly when considering prolonged empathic engagement and the potential effects thereof. Some work has been done regarding the positive impacts of technology in trauma-related work (i.e., for client populations and employees; Stamm et al. 2007), as well as in using mobile devices for resilience interventions (Wood et al. 2017). Such research bears further elaboration, bearing in mind employee, work-group, and organizational wellbeing, as well as the existing research on work-life interfaces and technology (e.g., Diaz et al. 2012; Harris et al. 2015).

Moreover, humanitarian aid, volunteer, and non-profit and non-governmental aid workers are often exposed to trauma while also being outside of a familiar national setting and support system (e.g., Cardozo et al. 2012). Some existing research has explored empathy-based stress among domestic and/or international humanitarian aid workers (e.g., Musa and Hamid 2008; Shah et al. 2007; Veronese and Pepe 2017). However, there stands to be more exploration in this space about the applicability of different empathy-based strain constructs (as well as primary trauma and other confounding stress experiences) in addition to resiliency factors, intervention techniques, and selection and training ( $\mathrm{Ng}$ et al. 2012). Additional considerations of distinctly relevant forms of stress, such as "moral stress" caused by conflict between perceived ethical action and institutional obstacles to ethical action, might also be relevant in these contexts (Forster 2009; Nilsson et al. 2011).

Overall, to resolve issues regarding the structure and application of empathy-based strain constructs, it will be necessary for researchers to provide specific definitions of their construct(s) of choice, including their requisite components (e.g., compassion), and the theory/rationale supporting their occupational and contextual application. Establishing theoretical motivations for construct application across contexts will aid in supporting the extension and investigation of empathy-based stress across professions. Systematically investigating personal and contextual factors, in addition to "newer" contexts of work, may be helpful to this end as well. 


\section{How Does Qualitative Research Contribute to Our Understanding of Empathy-Based Stress?}

Qualitative research can be valuable given the state of conceptual and operational variability in the empathy-based stress literature (see Meadors et al. 2009; Newell and MacNeil 2010; Sprang and Craig 2015). There are many qualitative studies aimed at finding common themes to understand empathy-based stress, though these studies do not tend to replicate, coalesce, or use themes for scale development purposes.

One potential reason for a lack of replication within qualitative research is unrepresentative sampling. Sample sizes for qualitative research tend to be smaller than for quantitative research. For example, qualitative studies commonly employ purposive samples with approximately twenty participants (e.g., Hegney et al. 2014; Stevenson et al. 2011), whereas quantitative studies employ samples of approximately 100 or more participants at minimum (see Hunsaker et al. 2015; Townsend and Campbell 2009). It is understandable that sample sizes are low given the time-consuming nature of qualitative research. However, from a theoretical viewpoint, many qualitative studies aiming to find common themes across participants should aim to ensure a representative sample if these themes are intended to reflect a common empathy-based stress process (Onwuegbuzie 2003). We recommend more rigorous qualitative methods to improve the literature and better identify whether discrepancies are a product of actual differences or, rather, of methodological issues.

Additionally, mixed-method studies, which attempt to triangulate data and improve methodological rigor (e.g., Cohen et al. 2015; Killian 2008; Sandelowski 1993), may be of value to improve qualitative research in the empathy-based stress literature and its integration with quantitative research. In qualitative studies, themes often closely relate to pre-existing constructs within the quantitative organizational research on occupational health (e.g., self-efficacy, work-family conflict, organizational culture; Dombo and Blome 2016; Lu et al. 2017; Tavormina and Clossey 2017). Thus, triangulating qualitative findings with quantitative findings across studies could improve conceptual clarity in the empathy-based stress literature.

\section{What Is the Temporal Nature of Empathy-Based Stress?}

In order to address a major gap in the literature, the temporality of empathy-based stress, quantitative research will be beneficial. Measurement, study design (i.e., causality and structure in intervention, multi-time point, and multilevel studies), and analysis are primary areas for improvement to fill this knowledge gap.

\section{How Should We Measure Empathy-Based Stress?}

Current practices in empathy-based stress measurement may be insufficient to uncover information about the temporal nature of empathy-based stress. Indeed, the sufficiency of psychometric evidence for existing measures has been debated for over a decade (Bride et al. 2007; Sabo 2006), with continued calls for more rigorous validation efforts (Beck 2011; Coetzee and Klopper 2010). For purposes of this discussion, we place particular emphasis on the two most widely used measures of empathy-based strain: the Professional Quality of Life scale (ProQOL, Stamm 2010) and the Secondary Traumatic Stress Scale (STSS, Bride et al. 2004). 
Initial factor analytic evidence for the STSS (Bride et al. 2004) revealed three-factor (intrusion, avoidance, arousal) loadings consistent with theory, but subsequent studies found equal (Ting et al. 2005) or superior (Vio and Vidallet 2007) support for a one-factor model. Moreover, studies with the ProQOL have revealed problematic reverse-coded items, differential item functioning, and improper factor loadings (Galiana et al. 2017; Hemsworth et al. 2018; Heritage et al. 2018; Samson et al. 2016). Unfortunately, studies examining measures' convergent or discriminant validity, independently or concurrently, are few and far between. Self-report measures are almost unanimously used to provide support for convergent validity, though common method variance (Podsakoff et al. 2003) is not considered when drawing conclusions. Divergent validity evidence has relied primarily upon demographic variables (Palestini et al. 2009; Vio and Vidallet 2007). As demographic variables are merely proxies for substantial variables (i.e., are nuisance variables with respect to the nomological network, Meehl 1970), demographics cannot offer convincing evidence in support of either discriminant or convergent validity.

\section{How Should We Design Studies of Empathy-Based Stress?}

With respect to study design, it is important to note that much of what is known about empathy-based stress comes from cross-sectional research. As a result, causal inferences are derived primarily from theory and a handful of studies inappropriately testing for "mediation" with cross-sectional data (e.g., Kleiner and Wallace 2017; Prati et al. 2011). Random assignment and temporal precedence are required to make causal inferences (Cook and Campbell 1979), and certain designs lend greater certainty (Stone-Romero and Rosopa 2008). Unfortunately, only a small proportion of studies includes random assignment or multiple time point designs; more rigorous studies examining empathy-based stressors across time would contribute greatly to our current understanding of empathy-based stress.

In the causal empathy-based stress literature, interventions take center stage. However, control groups are rarely randomly assigned in these studies. Often, control groups and treatment groups in studies without random assignment are assigned based on practicality and systematically differ in potentially meaningful ways. For example, studies assigning participants into groups based upon job, work group, or organization (e.g., Crowder and Sears 2017; Grundlingh et al. 2017) present opportunities for higherlevel variables (e.g., workload, team culture, supervisor attitudes and behaviors, local resources), as well as individual differences related to self-selection, to act as confounding factors. Of the studies that do employ random assignment, approximately half of the randomly assigned studies employ no-treatment control groups (e.g., Cieslak et al. 2016; Novoa and Cain 2014), whereas the remainder of random assignment studies tends to employ alternative-treatment control groups (e.g., Berger et al. 2016; Riley et al. 2017; Singh et al. 2018; Wylde et al. 2017). In general, more studies employing random assignment to conditions are needed. Moreover, as intervention studies frequently make inferences regarding a treatment's effectiveness based upon only post-intervention measures taken immediately after the intervention ends (e.g., Kometiani 2017; Pfaff et al. 2017), or only long-term follow-ups (e.g., Berger and Gelkopf 2011; Davidson et al. 2017; Noullet et al. 2018), more work is needed to determine sustained impact.

Outside of empathy-based intervention studies, other causal studies require design considerations for assessing the temporal nature of empathy-based stress. Longitudinal or multi-time point empathy-based stress studies vary in lags, with common use of one-month 
(e.g., Craigie et al. 2016; Weidlich and Ugarriza 2015), three-month (Allen et al. 2017; Riley et al. 2017) and six-month follow-ups (e.g., Shoji et al. 2014; Slatyer et al. 2018). Evidence suggests that burnout and secondary traumatic stress are relatively stable over these time periods (Craun et al. 2014). However, authors rarely offer explanations to justify time lag decisions (e.g., Riley et al. 2017; Shoji et al. 2015). In light of potential individual and contextual influences on the emergence and experience of empathy-based strains, we recommend that future studies include clear justification for the their chosen time lag.

More diverse methodologies may help to tease apart temporal relationships as well (e.g., experience-sampling and burst methodologies, Csikszentmihalyi and Larson 2014; Nesselroade 1991; longer-term, career-spanning effects). They can help to assess the nature of intradindividual fluctuations and interindividual differences across different levels of analysis (e.g., day- or week-level, within- and between-person) as well as the presence of empathy-based stress process growth curves and "spiral" effects. Charting effects over longer periods of time may be particularly relevant for outcomes such as employees' long-term wellbeing, as well as intentions and behaviors pertaining to organizational or occupational withdrawal. Such work would also, in part, address the lack of multilevel considerations included in study design and analysis in the empathy-based stress literature, particularly with respect to empathy-based stress emergence. Although "team" and "organization" factors are studied as risks and protections for employees in trauma-related work, they are modeled at the individual level of analysis (cf. Sprang et al. 2017's organizational assessment). Qualitative data regarding climate and organizational features suggest that higher-level factors play a role in the experience of empathy-based stress (e.g., Dombo and Blome 2016; Pross and Schweitzer 2010), and using data from specific organizations implies at least some homogeneity (i.e., non-independence). More explicit consideration of these factors in a multilevel framework is needed.

\section{How Should We Analyze Empathy-Based Stress Data?}

As data analysis greatly impacts the inferences that can be made and conclusions drawn from empathy-based stress studies, this is the final knowledge gap upon which we focus. Empathy-based stress measures are intended to be "screening" rather than "diagnostic" tools (e.g., Sinclair et al. 2017; Stamm 2010). As such, the interpretation of scores is often accomplished by using validated "cut-offs" that divide participants into (risk) severity (e.g., Munger et al. 2015) and/or percentile categories (e.g., Caringi et al. 2017). Using a cut-off approach prompts researchers to convert and report most to all of their variables, even those that are continuous to begin with, as categorical variables (e.g., Mangoulia et al. 2015; Stewart 2012). We suggest that viewing empathy-based stress variables (and their predictors and outcomes) continuously rather than categorically could help combat what Kunst et al. (2017) refer to as the "overmedicalization" of (empathy-based) stress responses (Kunst et al. 2017). Particularly given the positive skew (i.e., low "risk"/incidence rates) found in the literature, it could be that examining empathy-based stress variables on a continuum would be more useful and representative. At the very least, it would allow more nuance to be captured in analyses, and we recommend researchers take this approach.

Additionally, categorically oriented studies often have one-way analyses of variance and follow-up group comparisons that lack error rate adjustments (e.g., to significance test criteria) and/or a priori and theory-driven rationale for creating the categorical clusters used in group comparisons (e.g., age, tenure, "generation" groups; Kelly et al. 2015; Verhaeghe 
et al. 2016; Yu et al. 2016). This approach produces a body of research that has an overwhelming number of comparisons and is often practically uninterpretable and translatable into additional research or theory-building. A large proportion of studies in the empathy-based stress literature use stepwise regression and other inductive, modelbuilding approaches that do not aid in theory and research codification (e.g., Bourke and Craun 2014; Hunsaker et al. 2015; Lane et al. 2010; Setti et al. 2016; Verhaeghe et al. 2016). Overreliance on model-building approaches capitalizes on chance, a problem magnified even more when considering the fact that many studies use convenience sampling and single-source, single time-point procedures. We recommend that researchers take more theory-driven analytic approaches, such as more use of specific hypothesis testing and the inspection of confidence intervals and effect sizes in addition to statistical significance tests.

By taking these steps, in addition to changes to measurement and study design, the temporal nature of empathy-based stress can be better illuminated, and theory and evidence-based practice can be furthered in this space.

\section{An Occupational Health Research Agenda for Empathy-Based Stress}

In our final section, we present specific recommendations for the study and practice of empathy-based stress moving forward, guided by our review of the literature and its knowledge gaps. These recommendations aim to be integrative in nature, helping to chart the future course of empathy-based stress as a fundamental occupational health concern.

\section{Theoretical Recommendations}

As noted in the beginning of our review, existing work stress theory from the occupational health and organizational sciences literatures can and should be beneficially integrated with the frameworks and concepts used to study empathy-based stress. Our model is but a starting point for such an integration, and we encourage researchers to elaborate upon this with more nuanced theoretical linkages and boundary conditions. Organizational and occupational health literatures can be leveraged to explore individual differences (e.g., personality traits) and job attributes (i.e., demands and resources) that characterize the emergence of empathy-based strains and other wellbeing and work-relevant outcomes. To start, these could include particular trauma stressors (i.e., distressing, episodic, chronic), empathic engagements (e.g., expected as a part of job performance vs. engaged in proactively), and temporal properties (e.g., constant vs. sporadic, predictable vs. unpredictable).

While the COR and JD-R models were of most apparent relevance for the present review, additional theories of work stress such as work on person-environment fit may be helpful for future integration efforts. This is especially the true for efforts exploring workplace climate and/or occupational context factors in a codified fashion, or explaining the incidence of posttraumatic growth or compassion satisfaction (see reviews and recommendations from Edwards 1996; Edwards and Cooper 1990; see also Kulkarni et al. 2013 for an existing example). Work on challenge and hindrance stressors (e.g., Podsakoff et al. 2007; Van den Broeck et al. 2010) and the concept of eustress more broadly (Selye 1974) could be integrated with constructs in the empathybased stress literature to explain divergent responses to trauma exposure and empathic engagement at work. The potential for cross-cultural differences in stressor perceptions 
and processes, particularly in light of differences in posttraumatic stress disorder prevalence (e.g., Dückers et al. 2016) and other empathy-based stress mechanisms (e.g., empathic concern; Chopik et al. 2017), should be theoretically outlined and explored as well. Emotional labor and emotion regulation perspectives (e.g., Brotheridge and Grandey 2002; Grandey 2000), and work on "toxin handlers" (i.e., individuals who help peers deal with negative emotions; Kulik et al. 2009) and emotion capacity in organizational units (e.g., Stephens et al. 2013), may help extend empathybased stress phenomena into the occupational health literature. Models of empathy and its role as a form of emotional labor (e.g., Larson and Yao 2005), could be helpful to leverage to this end. Finally, perspectives on the various temporal trajectories (e.g., "sleeper" effects vs. synchronous effects) studied in the occupational health literature should be combined with existing theoretical perspectives on empathy-based stress to explicate its applications, incidence, and outcomes (Ford et al. 2014).

Although we primarily note areas in which occupational health theory and concepts can be utilized in the study of empathy-based stress, empathy-based stress is an important, trauma-informed addition to our understanding of worker wellbeing in occupational health more broadly. With increased consciousness of and attention to the incidence of workplace traumas such as sexual harassment and assault, broadening the study of empathy-based stress to include all occupations, and strengthening its theory, research, and practice with existing occupational health perspectives, is of the utmost importance. Moreover, the consideration of empathy-based strain constructs in the context of occupational health resilience studies may benefit be mutually beneficial (e.g., in answering calls for boundary conditions of resilience, additional relevant populations, temporal considerations; Britt et al. 2016).

\section{Empirical Recommendations}

The primary area we note as ripe for future research is the expansion of process models of empathy-based stress, such as the one developed herein, through the identification and empirical testing of underlying empathy-based stress mechanisms. For example, how does empathy-based stress arise and unfold over time? Are there particular "triggers" of which individuals and workplaces should be aware (e.g., particular demands or particular resource losses/threats), or particular "stages" during which individuals are most vulnerable to empathy-based stress (e.g., in their career, in an empathizing process, in a workday)? Can compassion fatigue, secondary traumatic stress, and vicarious trauma be mapped out temporally and structurally as distinct from one another and from burnout? Do they respond to "treatment" in different ways? What distinguishes those who are resilient to empathy-based stress from those who are not? Answers to these questions will not only support theoretical and empirical expansion, but also, and most importantly, effective and well-timed intervention.

In order to conduct research on empathy-based stress mechanisms, we anticipate that a few areas of the recent literature may be of particular interest to researchers and practitioners. First, recent work by Ludick and Figley (2017) in expanding the fatigue etiological model, as well as by Coddington (2017) in raising the possibility of vicarious "contagion", warrant further theoretical and research attention (see also Galek et al. 2011). We recommend that researchers adopt multilevel and multi-person investigations (e.g., of dyads, work teams, social networks) to examine potential social 
mechanisms and empathy-based stress "spread" in organizations. Novel investigations utilizing brain imaging technology (e.g., functional magnetic resonance imaging) might also be an intriguing methodology to leverage, as empathy-based stress processes have recently been considered from a neuroscience perspective (e.g., trauma transference, empathic responses, mirror neurons, limbic system function; see Decety et al. 2010; Ruysschaert 2009; Tyler 2012). Charting empathy-based stress at a neurobiological level may be of use in examining its emergence, development, and remediation through such practices as mindfulness and meditation (e.g., see Wheeler et al. 2017 for more on this topic). Moreover, these approaches can help differentiate between empathy-based stress and other forms of stress, as well as illuminate the physical structures and processes of empathy-based stress that are otherwise intangible in survey research. Work in the industrial-organizational psychology and occupational health literatures may be helpful to leverage here. This includes past work on affective processes in groups and organizations (Barsade and Knight 2015; George 2001), and work on different forms of stressor-strain relationships that characterize relationships (e.g., Ford et al. 2014) and/or social (e.g., Bliese and Britt 2001; Britt et al. 2008) or occupational (e.g., McClenahan et al. 2007; Sparks and Cooper 1999) contexts.

Similarly, physiological (sleep disturbances, raised cortisol levels; Bellicoso et al. 2017; Engert et al. 2014) and sociological/vocational mechanisms (e.g., career paths, role enactment over time; Schabram and Maitlis 2017) will be useful for future research into trajectories of empathy-based stress. These considerations will be valuable in examining the additive and/or multiplicative effects of empathic engagement over time (e.g., compounded strain versus a deepening sense of professional fulfillment) and the diverse ramifications of empathy-based stress experiences for future stress experiences (e.g., increased vulnerability vs. increased resilience due to sleep deficits and disillusioned vocational identity). In addition, such work will aid in identifying the areas upon which organizations should focus for facilitating physical health and sustainable "callings" for employees (e.g., sense of purpose; Schabram and Maitlis 2017). Again, integration with extant occupational health research, particularly with respect to physiological methodology "best practices" (e.g., see Eatough et al. 2016; Ganster 2008; Semmer et al. 2003) and existing frameworks linking physiology to work stressors, strains, and outcomes, will be helpful (e.g., Danna and Griffin 1999; Kuykendall and Tay 2015).

\section{Practical Recommendations}

We would be remiss to neglect the myriad practical implications of empathy-based stress that should be investigated, including preventative and ameliorative interventions. Although we mentioned some examples above, we believe that specific intervention approaches deserve additional attention, as does work regarding employee-workplace congruence and related interventions. To this latter point, Graham et al. (2016) conducted a recent study with a fit-based approach to predicting secondary traumatic stress and turnover intentions. The authors found that fit with workload, organizational values, and environment were predictive of secondary traumatic stress and turnover levels. Additional work about such issues, and particularly how relevant "types" of fit could be improved through selection and socialization, will be beneficial for mitigating empathy-based stress at work. "Front-end" realistic job previews for job candidates and training for new-hires, as well as provision of ongoing training and coping and recovery services at work for 
incumbents, will be relevant to consider in building an inclusive and resilient workforce (see Koerber et al. 2018 for a recent general review of such interventions).

The incorporation of empathy-based stress considerations in wellbeing programs and manager-led career development programs will prove useful as well. These can help to support workers across their careers; avoid costly absenteeism, turnover, and retraining; and build a talent base from which future leaders can emerge. Such talent will not only help sustain the organization and its mission. It can also help build valuable leader-follower mentoring relationships for generative knowledge transfer, and support a broader culture that allows employees to cope and maintain a sense of fulfillment (and even growth) from their work. Wellness and resilience training offerings that are too broad may not align with individual employee needs (e.g., see Robertson et al. 2015), so taking a specific and fit research-informed approach here will prove useful for effective practical interventions.

At the individual level, with regard to mindfulness-based interventions, research has been dedicated to developing and evaluating mindfulness training for secondhand traumaexposed employees (e.g., Craigie et al. 2016; Slatyer et al. 2018; Wood et al. 2017). We recommend that these efforts continue, including work to separate the influence of "trait" and "state" mindfulness (i.e., as in other areas of the literature; e.g., Medvedev et al. 2017), and to explore multi-part interventions with training in self-care techniques and at earlier career stages (e.g., during education and prior to formal employment; Tucker et al. 2017; Wald et al. 2016). Building interventions into earlier occupational and/or organizational entry stages may prove crucial for preventing empathy-based stress and sustaining employees' wellbeing across the lifespan; moreover, the method of delivery and source (e.g., peers, leaders and managers with differing levels of experience and leadership approaches) that optimize impact will be relevant to investigate as well. We recommend that researchers and practitioners focus on fit and mindfulness training moving forward to help prevent and support trauma-exposed workers in today's organizations. Extant reviews from the occupational health literature should be consulted in selecting, designing, implementing, and evaluating these interventions (Allen et al. 2015; Good et al. 2016; Jamieson and Tuckey 2017; Lomas et al. 2017).

In addition to mindfulness-based interventions, other preventative interventions such as meditation, writing workshops, mentoring programs, resiliency programs, and coping strategy training may be useful (Henry 2014; Ifrach and Miller 2016). To this latter point, coping strategies (i.e., problem-focused or emotion focused strategies) are used to prevent burnout (McArthur et al. 2017; Potter et al. 2013), and organizations can adapt these types of strategies, such as through wellness programs, to reduce the empathy-based strain experienced by their employees (Zadeh et al. 2012). As a plethora of large-scale interventions can be carried out, we encourage those who research future interventions to ground their work in line with best practices in the occupational health literature (e.g., Czabała et al. 2011; Israel et al. 1996; LaMontagne et al. 2007; Robertson et al. 2015).

\section{Limitations}

We acknowledge that this review, as well as our research agenda, is not without limitations. Our review is intentionally limited in scope, as we used the most common empathybased stress terminology employed and discussed the most pertinent and recurrent attributes of the literature within the past decade. It is quite possible that interesting and 
potentially fruitful explorations in the empathy-based stress literature were not, and could not be, included herein. However, the literature search and coding strategies we used, along with our clear parameters for literature evaluation, aimed to be much more inclusive than exclusive to help reduce this likelihood. Additionally, one could argue that, given the quantitative inconsistencies apparent in the empathy-based stress literature, a metaanalytic investigation would be of more value. While we do agree that a meta-analytic investigation may be of value in the future, we believe that the literature warranted a qualitative review before quantitative integration efforts. As mentioned earlier, metaanalyses have been conducted in the past but were limited due to variability in antecedents and outcomes considered, low sample sizes, divergent measurement approaches in the literature, and even divergence in how the same measurement approaches were used; future meta-analyses could explicitly consider this variability and heterogeneity, but our desire to generate an assessment and synthesis of the current state of the literature and a critical analysis-informed future research agenda could not be best accomplished using this approach. Thus, to achieve the aims of the present review, a qualitative synthesis was most appropriate. Our format allowed for deeper, focused discussion of conceptual issues and questions that should be addressed moving forward, as well as of recommendations for the improvement and application of empathy-based strain constructs, than could not be afforded through meta-analysis alone.

\section{Concluding Remarks}

Our review outlined the current state of the empathy-based stress literature, as well as some of the ways that it could be improved and elaborated upon in future occupational health research and practice. Research studying compassion fatigue, secondary traumatic stress, and vicarious traumatization has expanded over the past decade, yet the empathy-based stress literature still has room to grow. After defining and describing the current state of the literature and providing a model of empathy-based stress, we discussed some conceptual, methodological, and analytical "knowledge gaps" in this area and how they could be built into a future occupational health research agenda. The study of empathy-based stress has much to contribute to our understanding of trauma and empathy in work contexts, and this review serves as a synthesis-based introduction and agenda for theory, research, and practice to come.

\section{Compliance with Ethical Standards}

Conflict of Interest On behalf of all authors, the corresponding author states that there is no conflict of interest.

\section{References}

Akinsulure-Smith, A. M., Keatley, E., \& Rasmussen, A. (2012). Responding to secondary traumatic stress: a pilot study of torture treatment programs in the United States. Journal of Traumatic Stress, 25, 232-235. https://doi.org/10.1002/jts.21684. 
Allen, T. D., Eby, L. T., Conley, K. M., Williamson, R. L., Mancini, V. S., \& Mitchell, M. E. (2015). What do we really know about the effects of mindfulness-based training in the workplace? Industrial and Organizational Psychology, 8, 652-661. https://doi.org/10.1017/iop.2015.95.

Allen, R., Watt, F., Jansen, B., Coghlan, E., \& Nathan, E. A. (2017). Minimising compassion fatigue in obstetrics/gynaecology doctors: exploring an intervention for an occupational hazard. Australasian Psychiatry, 25, 403-406. https://doi.org/10.1177/1039856217700776.

American Psychiatric Association. (2013). Diagnostic and statistical manual of mental disorders (5th ed.). https://doi.org/10.1176/appi.books.9780890425596.

Austin, C. L., Saylor, R., \& Finley, P. J. (2017). Moral distress in physicians and nurses: impact on professional quality of life and turnover. Psychological Trauma: Theory, Research, Practice, and Policy, 9, 399-406. https://doi.org/10.1037/tra0000201.

Badger, K., Royse, D., \& Craig, C. (2008). Hospital social workers and indirect trauma exposure: an exploratory study of contributing factors. Health \& Social Work, 33, 63-71. https://doi.org/10.1093 /hsw/33.1.63.

Baird, K., \& Kracen, A. C. (2006). Vicarious traumatization and secondary traumatic stress: a research synthesis. Counselling Psychology Quarterly, 19, 181-188. https://doi.org/10.1080/09515070600811899.

Bakker, A. B., Demerouti, E., \& Verbeke, W. (2004). Using the job demands-resources model to predict burnout and performance. Human Resource Management, 43, 83-104. https://doi.org/10.1002/hrm.20004.

Baranik, L. E., Hurst, C. S., \& Eby, L. T. (2018). The stigma of being a refugee: a mixed-method study of refugees' experiences of vocational stress. Journal of Vocational Behavior, 105, 116-130. https://doi. org/10.1016/j.jvb.2017.09.006.

Barsade, S. G., \& Knight, A. P. (2015). Group affect. Annual Review of Organizational Psychology and Organizational Behavior, 2, 21-46. https://doi.org/10.1146/annurev-orgpsych-032414-111316.

Bauwens, J., \& Tosone, C. (2014). Posttraumatic growth following Hurricane Katrina: the influence of clinicians' trauma histories and primary and secondary traumatic stress. Traumatology, 20, 209-218. https://doi.org/10.1037/h0099851.

Bearse, J. L., McMinn, M. R., Seegobin, W., \& Free, K. (2013). Barriers to psychologists seeking mental health care. Professional Psychology: Research and Practice, 44, 150-157. https://doi.org/10.1037/a0031182.

Beck, C. T. (2011). Secondary traumatic stress in nurses: a systematic review. Archives of Psychiatric Nursing, 25, 1-10. https://doi.org/10.1016/j.apnu.2010.05.005.

Bellicoso, D., Trudeau, M., Fitch, M. I., \& Ralph, M. R. (2017). Chronobiological factors for compassion satisfaction and fatigue among ambulatory oncology caregivers. Chronobiology International, 34, 808818. https://doi.org/10.1080/07420528.2017.1314301.

Berger, R., \& Gelkopf, M. (2011). An intervention for reducing secondary traumatization and improving professional self-efficacy in well baby clinic nurses following war and terror: a random control group trial. International Journal of Nursing Studies, 48, 601-610. https://doi.org/10.1016/j.ijnurstu.2010.09.007.

Berger, R., Abu-Raiya, H., \& Benatov, J. (2016). Reducing primary and secondary traumatic stress symptoms among educators by training them to deliver a resiliency program (ERASE-stress) following the Christchurch earthquake in New Zealand. American Journal of Orthopsychiatry, 86, 236-251. https://doi.org/10.1037/ort0000153.

Birinci, G. G., \& Erden, G. (2016). Evaluation of vicarious trauma, secondary traumatic stress and burnout in aid workers. Türk Psikoloji Dergisi, 31, 10-26.

Bliese, P. D., \& Britt, T. W. (2001). Social support, group consensus and stressor-strain relationships: social context matters. Journal of Organizational Behavior, 22, 425-436. https://doi.org/10.1002/job.95.

Borntrager, C., Caringi, J. C., van den Pol, R., Crosby, L., O'Connell, K., Trautman, A., \& McDonald, M. (2012). Secondary traumatic stress in school personnel. Advances in School Mental Health Promotion, 5 , 38-50. https://doi.org/10.1080/1754730x.2012.664862.

Bourke, M. L., \& Craun, S. W. (2014). Secondary traumatic stress among internet crimes against children task force personnel: impact, risk factors, and coping strategies. Sexual Abuse, 26, 586-609. https://doi. org/10.1177/1079063213509411.

Bride, B. E., \& Kintzle, S. (2011). Secondary traumatic stress, job satisfaction, and occupational commitment in substance abuse counselors. Traumatology, 17, 22-28. https://doi.org/10.1177/1534765610395617.

Bride, B. E., Robinson, M. R., Yegidis, B., \& Figley, C. R. (2004). Development and validation of the secondary traumatic stress scale. Research on Social Work Practice, 14, 27-35. https://doi.org/10.1177 $/ 1049731503254106$.

Bride, B. E., Radey, M., \& Figley, C. R. (2007). Measuring compassion fatigue. Clinical Social Work Journal, 35, 155-163. https://doi.org/10.1007/s10615-007-0091-7.

Britt, T. W., Greene-Shortridge, T. M., Brink, S., Nguyen, Q. B., Rath, J., Cox, A. L., et al. (2008). Perceived stigma and barriers to care for psychological treatment: Implications for reactions to stressors in different 
contexts. Journal of Social and Clinical Psychology, 27, 317-335. https://doi.org/10.1521 /jscp.2008.27.4.317.

Britt, T. W., Shen, W., Sinclair, R. R., Grossman, M. R., \& Klieger, D. M. (2016). How much do we really know about employee resilience? Industrial and Organizational Psychology, 9, 378-404. https://oi. org/10.1017/iop.2015.107.

Brotheridge, C. M., \& Grandey, A. A. (2002). Emotional labor and burnout: comparing two perspectives of “people work". Journal of Vocational Behavior, 60, 17-39. https://doi.org/10.1006/jvbe.2001.1815.

Brown, J. L. C., Ong, J., Mathers, J. M., \& Decker, J. T. (2017). Compassion fatigue and mindfulness: comparing mental health professionals and MSW student interns. Journal of Evidence-Informed Social Work, 14, 119-130. https://doi.org/10.1080/23761407.2017.1302859.

Buckner, G. E., Hindman, H. D., Huelsman, T. J., \& Bergman, J. Z. (2014). Managing workplace sexual harassment: the role of manager training. Employee Responsibilities and Rights Journal, 26, 257-278. https://doi.org/10.1007/s10672-014-9248-Z.

Butler, L. D., Carello, J., \& Maguin, E. (2017). Trauma, stress, and self-care in clinical training: Predictors of burnout, decline in health status, secondary traumatic stress symptoms, and compassion satisfaction. Psychological Trauma: Theory, Research, Practice, and Policy, 9, 416-424. https://doi.org/10.1037 /tra0000187.

Cardozo, B. L., Crawford, C. G., Eriksson, C., Zhu, J., Sabin, M., Ager, A., et al. (2012). Psychological distress, depression, anxiety, and burnout among international humanitarian aid workers: a longitudinal study. PLoS One, 7, 1-13. https://doi.org/10.1371/journal.pone.0044948.

Caringi, J. C., Hardlman, E. R., Weldon, P., Fletcher, S., Devlin, M., \& Stanick, C. (2017). Secondary traumatic stress and licensed clinical social workers. Traumatology, 23, 186-195. https://doi.org/10.1037 /trm0000061.

Choi, G.-Y. (2017). Secondary traumatic stress and empowerment among social workers working with family violence or sexual assault survivors. Journal of Social Work, 17, 358-378. https://doi.org/10.1177 $/ 1468017316640194$.

Chopik, W. J., O’Brien, E., \& Konrath, S. H. (2017). Differences in empathic concern and perspective taking across 63 countries. Journal of Cross-Cultural Psychology, 48, 23-38. https://doi.org/10.1177 $/ 0022022116673910$.

Cieslak, R., Shoji, K., Douglas, A., Melville, E., Luszczynska, A., \& Benight, C. C. (2014). A meta-analysis of the relationship between job burnout and secondary traumatic stress among workers with indirect exposure to trauma. Psychological Services, 11, 75-86. https://doi.org/10.1037/a0033798.

Cieslak, R., Benight, C. C., Rogala, A., Smoktunowicz, E., Kowalska, M., Zukowska, K., et al. (2016). Effects of internet-based self-efficacy intervention on secondary traumatic stress and secondary posttraumatic growth among health and human services professionals exposed to indirect trauma. Frontiers in Psychology, 7, 1009. https://doi.org/10.3389/fpsyg.2016.01009.

Coddington, K. S. (2017). Contagious trauma: reframing the spatial mobility of trauma within advocacy work. Emotion, Space and Society, 24, 66-73. https://doi.org/10.1016/j.emospa.2016.02.002.

Coetzee, S. K., \& Klopper, H. C. (2010). Compassion fatigue within nursing practice: a concept analysis. Nursing \& Health Sciences, 12, 235-243. https://doi.org/10.1111/j.1442-2018.2010.00526.x.

Cohen, K., \& Collens, P. (2013). The impact of trauma work on trauma workers: a metasynthesis on vicarious trauma and vicarious posttraumatic growth. Psychological Trauma: Theory, Research, Practice, and Policy, 5, 570-580. https://doi.org/10.1037/a0030388.

Cohen, E., Roer-Strier, D., Menachem, M., Fingher-Amital, S., \& Israeli, N. (2015). "Common-fate": therapists' benefits and perils in conducting child therapy following the shared traumatic reality of war. Clinical Social Work Journal, 43, 77-88. https://doi.org/10.1007/s10615-014-0499-9.

Colligan, T. W., \& Higgins, E. M. (2006). Workplace stress: etiology and consequences. Journal of Workplace Behavioral Health, 21, 89-97. https://doi.org/10.1300/j490v21n02_07.

Cook, T. D., \& Campbell, D. T. (1979). Quasi-experimentation: Design and analysis issues for field settings. Chicago: Rand McNally.

Cragun, J. N., April, M. D., \& Thaxton, R. E. (2016). The impact of combat deployment on health care provider burnout in a military emergency department: a cross-sectional professional quality of life scale $\mathrm{V}$ survey study. Military Medicine, 18, 730-734. https://doi.org/10.7205/MILMED-D-15-00420.

Craig, C. D., \& Sprang, G. (2010). Compassion satisfaction, compassion fatigue, and burnout in a national sample of trauma treatment therapists. Anxiety, Stress \& Coping, 23, 319-339. https://doi.org/10.1080 /10615800903085818.

Craigie, M., Slatyer, S., Hegney, D., Osselran-Moisson, R., Gentry, E., et al. (2016). A pilot evaluation of a mindful self-care and resiliency (MSCR) intervention for nurses. Mindfulness, 7, 764-774. https://doi. org/10.1007/s12671-016-0516-X. 
Craun, S. W., \& Bourke, M. L. (2014). The use of humor to cope with secondary traumatic stress. Journal of Child Sexual Abuse, 23, 840-852. https://doi.org/10.1080/10538712.2014.949395.

Craun, S. W., Bourke, M. L., Bierie, D. M., \& Williams, K. S. (2014). A longitudinal examination of secondary traumatic stress among law enforcement. Victims \& Offenders, 9, 299-316. https://doi. org/10.1080/15564886.2013.848828.

Crowder, R., \& Sears, A. (2017). Building resilience in social workers: an exploratory study on the impacts of a mindfulness-based intervention. Australian Social Work, 70, 17-29. https://doi.org/10.1080/0312407 x.2016.1203965.

Csikszentmihalyi, M., \& Larson, R. (2014). Validity and reliability of the experience-sampling method. In Flow and the foundations of positive psychology (pp. 35-54). Dordrecht: Springer.

Czabała, C., Charzyńska, K., \& Mroziak, B. (2011). Psychosocial interventions in workplace mental health promotion: an overview. Health Promotion International, 26, i70-i84. https://doi.org/10.1093 /heapro/dar050.

Dagan, S. W., Ben-Porat, A., \& Itzhaky, H. (2016). Child protection workers dealing with child abuse: the contribution of personal, social and organizational resources to secondary traumatization. Child Abuse \& Neglect, 51, 203-211. https://doi.org/10.1016/j.chiabu.2015.10.008.

Danna, K., \& Griffin, R. W. (1999). Health and well-being in the workplace: a review and synthesis of the literature. Journal of Management, 25, 357-384. https://doi.org/10.1016/s0149-2063(99)00006-9.

Davidson, J. E., Graham, P., Montross-Thomas, L., Norcross, W., \& Zerbi, G. (2017). Code Lavender: cultivating intentional acts of kindness in response to stressful work situations. Explore, 13, 181-185. https://doi.org/10.1016/j.explore.2017.02.005.

Day, M. C., Bond, K., \& Smith, B. (2013). Holding it together: coping with vicarious trauma in sport. Psychology of Sport and Exercise, 14, 1-11. https://doi.org/10.1016/j.psychsport.2012.06.001.

Decety, J., Yang, C.-Y., \& Cheng, Y. (2010). Physicians down-regulate their pain empathy response: an eventrelated brain potential study. NeuroImage, 50, 1676-1682. https://doi.org/10.1016/j. neuroimage.2010.01.025.

Decker, J. T., Brown, J. L. C., Ong, J., \& Stiney-Zisknd, C. A. (2015). Mindfulness, compassion fatigue, and compassion satisfaction among social work interns. Social Work \& Christianity, 42, 28-42.

Demerouti, E., Bakker, A. B., Nachreiner, F., \& Schaufeli, W. B. (2001). The job demands-resources model of burnout. Journal of Applied Psychology, 86, 499-512. https://doi.org/10.1037/0021-9010.86.3.499.

Diaz, I., Chiaburu, D. S., Zimmerman, R. D., \& Boswell, W. R. (2012). Communication technology: pros and cons of constant connection to work. Journal of Vocational Behavior, 80, 500-508. https://doi. org/10.1016/j.jvb.2011.08.007.

Dombo, E. A., \& Blome, W. W. (2016). Vicarious trauma in child welfare workers: a study of organizational responses. Journal of Public Child Welfare, 10, 505-523. https://doi.org/10.1080 /15548732.2016.1206506.

Dückers, M. L., Alisic, E., \& Brewin, C. R. (2016). A vulnerability paradox in the cross-national prevalence of post-traumatic stress disorder. The British Journal of Psychiatry, 209, 300-305. https://doi.org/10.1192 /bjp.bp.115.176628.

Dutton, M. A., Dahlgren, S., Franco-Rahman, M., Martinez, M., Serrano, A., \& Mete, M. (2017). A holistic healing arts model for counselors, advocates, and lawyers serving trauma survivors: joyful Heart Foundation Retreat. Traumatology, 23, 143-152. https://doi.org/10.1037/trm0000109.

Dworkin, E. R., Sorell, N. R., \& Allen, N. E. (2016). Individual-and setting-level correlates of secondary traumatic stress in rape crisis center staff. Journal of Interpersonal Violence, 31, 743-752. https://doi. org/10.1177/0886260514556111.

Eatough, E., Shockley, K., \& Yu, P. (2016). A review of ambulatory health data collection methods for employee experience sampling research. Applied Psychology, 65, 322-354. https://doi.org/10.1111 /apps.12068.

Edwards, J. R. (1996). An examination of competing versions of the person-environment fit approach to stress. Academy of Management Journal, 39, 292-339. https://doi.org/10.2307/256782.

Edwards, J. R., \& Cooper, C. L. (1990). The person-environment fit approach to stress: recurring problems and some suggested solutions. Journal of Organizational Behavior, 11, 293-307. https://doi.org/10.1002 job.4030110405.

Engert, V., Plessow, F., Miller, R., Kirschbaum, C., \& Singer, T. (2014). Cortisol increase in empathic stress is modulated by emotional closeness and observation modality. Psychoneuroendocrinology, 45, 192-201. https://doi.org/10.1016/j.psyneuen.2014.04.005.

Ewer, P. L., Teesson, M., Sannibale, C., Roche, A., \& Mills, K. L. (2015). The prevalence and correlates of secondary traumatic stress among alcohol and other drug workers in Australia. Drug and Alcohol Review, 34, 252-258. https://doi.org/10.1111/dar.12204. 
Fernando, A. T., III, \& Consedine, N. S. (2017). Barriers to medical compassion as a function of experience and specialization: psychiatry, pediatrics, internal medicine, surgery, and general practice. Journal of Pain and Symptom Management, 53, 979-987. https://doi.org/10.1016/j.jpainsymman.2016.12.324.

Figley, C. R. (1993). Compassion stress: towards its measurement and management. Family Therapy News, 1-2.

Figley, C. R. (1995). Compassion fatigue: Toward a new understanding of the costs of caring. In B. H. Stamm (Ed.), Secondary traumatic stress: Self-care issues for clinicians, researchers, and educators (pp. 3-28). Baltimore: The Sidran Press.

Figley, C. R. (2002). Compassion fatigue: psychotherapists' chronic lack of self care. Journal of Clinical Psychology, 58, 1433-1441. https://doi.org/10.1002/jclp.10090.

Finzi-Dottan, R., \& Kormosh, M. B. (2018). The spillover of compassion fatigue into marital quality: a mediation model. Traumatology, 24, 113-122. https://doi.org/10.1037/trm0000137.

Ford, M. T., Matthews, R. A., Wooldridge, J. D., Mishra, V., Kakar, U. M., \& Strahan, S. R. (2014). How do occupational stressor-strain effects vary with time? A review and meta-analysis of the relevance of time lags in longitudinal studies. Work \& Stress, 28, 9-30. https://doi.org/10.1080/02678373.2013.877096.

Forster, D. (2009). Rethinking compassion fatigue as moral stress. Journal of Ethics in Mental Health, 4, 1-4 Retrieved from https://www.jemh.ca/issues/v4n1/documents/JEMH_Vol4_No1_Rethinking_ Compassion_Fatigue_as_Moral_Stress_apr_09-final.pdf. Accessed 15 Jan 2018

Galek, K., Flannelly, K. J., Greene, P. B., \& Kudler, T. (2011). Burnout, secondary traumatic stress, and social support. Pastoral Psychology, 60, 633-649. https://doi.org/10.1007/s11089-011-0346-7.

Galiana, L., Arena, F., Oliver, A., Sanso, N., \& Benito, E. (2017). Compassion satisfaction, compassion fatigue, and burnout in Spain and Brazil: ProQOL validation and cross-cultural diagnosis. Journal of Pain and Symptom Management, 53, 598-604. https://doi.org/10.1016/j.jpainsymman.2016.09.014.

Ganster, D. C. (2008). Measurement challenges for studying work-related stressors and strains. Human Resource Management Review, 18, 259-270. https://doi.org/10.1016/j.hrmr.2008.07.011.

George, J. M. (2001). Affect regulation in groups and teams. In R. G. Lord, R. J. Klimoski, \& R. Kanfer (Eds.), Emotions in the workplace: Understanding the structure and role of emotions in organizational behavior (pp. 183-217). San Francisco: Jossey-Bass.

Goldblatt, H. (2009). Caring for abused women: impact on nurses' professional and personal life experiences. Journal of Advanced Nursing, 65, 1645-1654. https://doi.org/10.1111/j.1365-2648.2009.05019.x.

Good, D. J., Lyddy, C. J., Glomb, T. M., Bono, J. E., Brown, K. W., Duffy, M. K., et al. (2016). Contemplating mindfulness at work: an integrative review. Journal of Management, 42, 114-142. https://doi.org/10.1177 /0149206315617003.

Graham, J. R., Shier, M. L., \& Nicholas, D. (2016). Workplace congruence and occupational outcomes among social service workers. British Journal of Social Work, 46, 1096-1114. https://doi.org/10.1093 /bjsw/bcu153.

Grandey, A. A. (2000). Emotional regulation in the workplace: a new way to conceptualize emotional labor. Journal of Occupational Health Psychology, 5, 95-110. https://doi.org/10.1037/1076-8998.5.1.95.

Grundlingh, H., Knight, L., Naker, D., \& Devries, K. (2017). Secondary distress in violence researchers: a randomised trial of the effectiveness of group debriefings. BMC Psychiatry, 17, 204. https://doi. org/10.1186/s12888-017-1327-x.

Haik, J., Brown, S., Liran, A., Visentin, D., Sokolov, A., Zilinsky, I., \& Kornhaber, R. (2017). Burnout and compassion fatigue: prevalence and associations among Israeli burn clinicians. Neuropsychiatric Disease and Treatment, 13, 1533-1540. https://doi.org/10.2147/NDT.S133181.

Harker, R., Pidgeon, A. M., Klaassen, F., \& King, S. (2016). Exploring resilience and mindfulness as preventative factors for psychological distress burnout and secondary traumatic stress among human service professionals. Work: Journal of Prevention, Assessment \& Rehabilitation, 54, 631-637. https://doi.org/10.3233/WOR-162311.

Harris, K. J., Harris, R. B., Carlson, J. R., \& Carlson, D. S. (2015). Resource loss from technology overload and its impact on work-family conflict: can leaders help? Computers in Human Behavior, 50, 411-417. https://doi.org/10.1016/j.chb.2015.04.023.

Hartig, T., Kylin, C., \& Johansson, G. (2007). The telework tradeoff: stress mitigation vs. constrained restoration. Applied Psychology, 56, 231-253. https://doi.org/10.1111/j.1464-0597.2006.00252.x.

Hatcher, R. M., \& Noakes, S. (2010). Working with sex offenders: the impact on Australian treatment providers. Psychology, Crime \& Law, 16, 145-167. https://doi.org/10.1080/10683160802622030.

Hegney, D. G., Craigie, M., Hemsworth, D., Osseiran-Moisson, R., Aoun, S., Francis, K., \& Drury, V. (2014). Compassion satisfaction, compassion fatigue, anxiety, depression, and stress in registered nurses in Australia: Study 1 results. Journal of Nursing Management, 22, 506-518. https://doi.org/10.1111 /jonm.12160. 
Hemsworth, D., Baregheh, A., Aoun, S., \& Kazanjian, A. (2018). A critical enquiry into the psychometric properties of the professional quality of life scale (ProQol-5) instrument. Applied Nursing Research, 39, 81-88. https://doi.org/10.1016/j.apnr.2017.09.006.

Henry, B. J. (2014). Nursing burnout interventions: what is being done? Clinical Journal of Oncology Nursing, 18, 211-214. https://doi.org/10.1188/14.cjon.211-214.

Hensel, J. M., Ruiz, C., Finney, C., \& Dewa, C. S. (2015). Meta-analysis of risk factors for secondary traumatic stress in therapeutic work with trauma victims. Journal of Traumatic Stress, 28, 83-91. https://doi.org/10.1002/jts.21998.

Heritage, B., Rees, C. S., \& Hegney, D. G. (2018). The ProQOL-21: a revised version of the professional quality of life (ProQOL) scale based on Rasch analysis. PLoS One, 13, e0193478. https://doi.org/10.1371 /journal.pone.0193478.

Hernández García, M. C. (2017). Compassion fatigue among health professionals in palliative care and oncology services. Psicooncología, 14, 53-70. https://doi.org/10.5209/PSIC.55811.

Hidalgo, J., Maravic, M. C., Milet, R. C., \& Beck, J. C. (2016). Promoting collaborative relationships in residential care of vulnerable and traumatized youth: a playfulness approach integrated with trauma systems therapy. Journal of Child \& Adolescent Trauma, 9, 17-28. https://doi.org/10.1007/s40653-0150076-6.

Hiles Howard, A. R., Parris, S., Hall, J. S., Call, C. D., Razuri, E. B., Purvis, K. B., \& Cross, D. R. (2015). An examination of the relationships between professional quality of life, adverse childhood experiences, resilience, and work environment in a sample of human service providers. Children and Youth Services Review, 57, 141-148. https://doi.org/10.1016/j.childyouth.2015.08.003.

Hobfoll, S. E. (1989). Conservation of resources: A new attempt at conceptualizing stress. American Psychologist, 44, 513-524. https://doi.org/10.1037/0003-066x.44.3.513.

Hobfoll, S. E. (2001). The influence of culture, community, and the nested-self in the stress process: advancing conservation of resources theory. Applied Psychology, 50, 337-421. https://doi.org/10.1111/14640597.00062 .

Hunsaker, S., Chen, H. C., Maughan, D., \& Heaston, S. (2015). Factors that influence the development of compassion fatigue, burnout, and compassion satisfaction in emergency department nurses. Journal of Nursing Scholarship, 47, 186-194. https://doi.org/10.1111/jnu.12122.

Ifrach, E. R., \& Miller, A. (2016). Social action art therapy as an intervention for compassion fatigue. The Arts in Psychotherapy, 50, 34-39. https://doi.org/10.1016/j.aip.2016.05.009.

Israel, B. A., Baker, E. A., Goldenhar, L. M., \& Heaney, C. A. (1996). Occupational stress, safety, and health: conceptual framework and principles for effective prevention interventions. Journal of Occupational Health Psychology, 1, 261-286. https://doi.org/10.1037/1076-8998.1.3.261.

Ivcic, R., \& Motta, R. (2017). Variables associated with secondary traumatic stress among mental health professionals. Traumatology, 23, 196-204. https://doi.org/10.1037/trm0000065.

Jakimowicz, S., Perry, L., \& Lewis, J. (2018). Insights on compassion and patient-centred nursing in intensive care: a constructivist grounded theory. Journal of Clinical Nursing, 27, 1599-1611. https://doi. org/10.1111/jocn.14231.

Jamieson, S. D., \& Tuckey, M. R. (2017). Mindfulness interventions in the workplace: a critique of the current state of the literature. Journal of Occupational Health Psychology, 22, 180-193. https://doi.org/10.1037 /ocp0000048.

Jarrad, R., Hammad, S., Shawashi, T., \& Mahmoud, N. (2018). Compassion fatigue and substance use among nurses. Annals of General Psychiatry, 17, 13. https://doi.org/10.1186/s12991-018-0183-5.

Jenkins, S. R., Mitchell, J. L., Baird, S., Whitfield, S. R., \& Meyer, H. L. (2011). The counselor's trauma as counseling motivation: vulnerability or stress inoculation? Journal of Interpersonal Violence, 26, 23922412. https://doi.org/10.1177/0886260510383020.

Joinson, C. (1992). Coping with compassion fatigue. Nursing, 22, 116-121. https://doi.org/10.1097 /00152193-199204000-00035.

Kaewpan, W., Peltzer, K., Kalampakorn, S., \& Moolsart, S. (2017). Professional quality of life among postretired academic university employees in Thailand. Social Behavior and Personality, 45, 669-676. https://doi.org/10.2224/sbp.5913.

Keenan, P., \& Royle, L. (2007). Vicarious trauma and first responders: a case study utilizing eye movement desensitization and reprocessing (EMDR) as the primary treatment modality. International Journal of Emergency Mental Health, 9, 291-298.

Kelley, T. L. (1927). Interpretation of educational measurements. Oxford: World Book Co..

Kelly, L., Runge, J., \& Spencer, C. (2015). Predictors of compassion fatigue and compassion satisfaction in acute care nurses. Journal of Nursing Scholarship, 47, 522-528. https://doi.org/10.1111/jnu.12162. 
Killian, K. D. (2008). Helping till it hurts? A multimethod study of compassion fatigue, burnout, and self-care in clinicians working with trauma survivors. Traumatology, 14, 32-44. https://doi.org/10.1177 $/ 1534765608319083$.

Kilpatrick, D. G., Resnick, H. S., Milanak, M. E., Miller, M. W., Keyes, K. M., \& Friedman, M. J. (2013). National estimates of exposure to traumatic events and PTSD prevalence using DSM-IV and DSM-V criteria. Journal of Traumatic Stress, 26, 537-547. https://doi.org/10.1002/jts.21848.

Kim, Y. J. (2017). Secondary traumatic stress and burnout of north Korean refugees service providers. Korean Neuropsychiatric Association, 14, 118-125. https://doi.org/10.4306/pi.2017.14.2.118.

Kim, Y. H., Kim, S. R., Kim, Y. O., Kim, J. Y., Kim, H. K., \& Kim, H. Y. (2017). Influence of type D personality on job stress and job satisfaction in clinical nurses: the mediating effects of compassion fatigue, burnout, and compassion satisfaction. Journal of Advanced Nursing, 73, 905-916. https://doi. org/10.1111/jan.13177.

Kindermann, D., Schmid, C., Derrez-Greeven, C., Huhn, D., Kohl, R. M., Junne, F., et al. (2017). Prevalence of and risk factors for secondary traumatization in interpreters for refugees: a cross-sectional study. Psychopathology, 50, 262-272. https://doi.org/10.1159/000477670.

Kita, E. (2015). Public safety, psychological security: A practice-informed research study exploring how California parole agents experience their work. Smith College Studies in Social Work, 85, 5-29. https://doi.org/10.1080/00377317.2015.957597.

Kitchingman, T. A., Wilson, C. J., Woodward, A., Caputi, P., \& Wilson, I. (2017). Telephone crisis support workers' intentions to use recommended skills while experiencing functional impairment. Crisis, 39, 218 223. https://doi.org/10.1027/0227-5910/a000490.

Kiyimba, N., \& O'Reilly, M. (2016). The risk of secondary traumatic stress in the qualitative transcription process: a research note. Qualitative Research, 16, 468-476. https://doi.org/10.1177/1468794115577013.

Kleiner, S., \& Wallace, J. E. (2017). Oncologist burnout and compassion fatigue: investigating time pressure at work as a predictor and the mediating role of work-family conflict. BMC Health Services Research, 17, 639-647. https://doi.org/10.1186/s12913-017-2581-9.

Koerber, R., Rouse, M., Stanyar, K., \& Pelletier, M.-H. (2018). Building resilience in the workforce. Organizational Dynamics, 47, 124-134. https://doi.org/10.1016/j.orgdyn.2017.08.002.

Kometiani, M. K. (2017). Creating a vital healing community: a pilot study of an art therapy employee support group at a pediatric hospital. The Arts in Psychotherapy, 54, 122-127. https://doi.org/10.1016/j. aip.2017.04.012.

Kulik, C. T., Cregan, C., Metz, I., \& Brown, M. (2009). HR managers as toxin handlers: the buffering effect of formalizing toxin handling responsibilities. Human Resource Management, 48, 695-716. https://doi. org/10.1002/hrm.20311.

Kulkarni, S., Bell, H., Hartman, J. L., \& Herman-Smith, R. L. (2013). Exploring individual and organizational factors contributing to compassion satisfaction, secondary traumatic stress, and burnout in domestic violence service providers. Journal of the Society for Social Work and Research, 4, 114-130. https://doi.org/10.5243/jsswr.2013.8.

Kunst, M. J. J., Saan, M. C., Bollen, L. J. A., \& Kuijpers, K. F. (2017). Secondary traumatic stress and secondary posttraumatic growth in a sample of Dutch police family liaison officers. Stress and Health, 33, 570-577. https://doi.org/10.1002/smi.2741.

Kuykendall, L., \& Tay, L. (2015). Employee subjective well-being and physiological functioning: an integrative model. Health psychology Open, 2. https://doi.org/10.1177/2055102915592090.

LaFauci Schutt, J. M., \& Marotta, S. A. (2011). Personal and environmental predictors of posttraumatic stress in emergency management professionals. Psychological Trauma: Theory, Research, Practice, and Policy, 3, 8-15. https://doi.org/10.1037/a0020588.

LaMontagne, A. D., Keegel, T., Louie, A. M., Ostry, A., \& Landsbergis, P. A. (2007). A systematic review of the job-stress intervention evaluation literature, 1990-2005. International Journal of Occupational and Environmental Health, 13, 268-280. https://doi.org/10.1179/oeh.2007.13.3.268.

Lane, E. J., Lating, J. M., Lowry, J. L., \& Martino, T. P. (2010). Differences in compassion fatigue, symptoms of posttraumatic stress disorder and relationship satisfaction, including sexual desire and functioning, between male and female detectives who investigate sexual offenses against children: a pilot study. International Journal of Emergency Mental Health, 12, 257-266.

Larson, E. B., \& Yao, X. (2005). Clinical empathy as emotional labor in the patient-physician relationship. JAMA, 293, 1100-1106. https://doi.org/10.1001/jama.293.9.1100.

Latimer, M., Jackson, P. L., Eugène, F., Macleod, E., Hatfield, T., Vachon-Presseau, E., et al. (2017). Empathy in pediatric intensive care nurses part 1: behavioral and psychological correlates. Journal of Advanced Nursing, 73, 2676-2685. https://doi.org/10.1111/jan.13333. 
Lazarus, J. (2000). Stress relief \& relaxation techniques. Los Angeles: NTC/Contemporary Publishing Group, Inc..

Leake, R., Rienks, S., \& Obermann, A. (2017). A deeper look at burnout in the child welfare workforce. Human Service Organizations: Management, Leadership \& Governance, 41, 492-502. https://doi. org/10.1080/23303131.2017.1340385.

Ledoux, K. (2015). Understanding compassion fatigue: Understanding compassion. Journal of Advanced Nursing, 71, 2041-2050. https://doi.org/10.1111/jan.12686.

Lev-Wiesel, R., Goldblatt, H., Eisikovits, Z., \& Admi, H. (2009). Growth in the shadow of war: the case of social workers and nurses working in a shared war reality. British Journal of Social Work, 39, 1154-1174. https://doi.org/10.1093/bjsw/ben021.

Levy, H. C., Conoscenti, L. M., Tillery, J. F., Dickstein, B. D., \& Litz, B. T. (2011). Deployment stressors and outcomes among air force chaplains. Journal of Traumatic Stress, 24, 342-346. https://doi.org/10.1002 /jts.20646.

Li, A., Early, S. F., Mahrer, N. E., Klaristenfeld, J. L., \& Gold, J. I. (2014). Group cohesion and organizational commitment: protective factors for nurse residents' job satisfaction, compassion fatigue, compassion satisfaction, and burnout. Journal of Professional Nursing, 30, 89-99. https://doi.org/10.1016/j. profnurs.2013.04.004.

Linnerooth, P. J., Mrdjenovich, A. J., \& Moore, B. A. (2011). Professional burnout in clinical military psychologists: recommendations before, during, and after deployment. Professional Psychology: Research and Practice, 42, 87-93. https://doi.org/10.1037/a0022295.

Locatelli, S. M., \& LaVela, S. L. (2015). Professional quality of life of veterans affairs staff and providers in a patient-centered care environment. The Health Care Manager, 34, 246-254. https://doi.org/10.1097 /hcm.0000000000000070.

Lomas, T., Medina, J. C., Ivtzan, I., Rupprecht, S., Hart, R., \& Eiroa-Orosa, F. J. (2017). The impact of mindfulness on well-being and performance in the workplace: an inclusive systematic review of the empirical literature. European Journal of Work and Organizational Psychology, 26, 492-513. https://doi. org/10.1080/1359432x.2017.1308924.

Lu, H.-T., Zhou, Y., \& Pillay, Y. (2017). Counselor education students' exposure to trauma cases. International Journal for the Advancement of Counselling, 39, 322-332. https://doi.org/10.1007/s10447-017-9300-4.

Ludick, M., \& Figley, C. R. (2017). Toward a mechanism for secondary trauma induction and reduction: reimagining a theory of secondary traumatic stress. Traumatology, 23, 112-123. https://doi.org/10.1037 $/$ trm0000096.

Mairean, C. (2016a). Emotion regulation strategies, secondary traumatic stress, and compassion satisfaction in healthcare providers. The Journal of Psychology: Interdisciplinary and Applied, 150, 961-975. https://doi.org/10.1080/00223980.2016.1225659.

Mairean, C. (2016b). The relationship between secondary traumatic stress and personal posttraumatic growth: personality factors as moderators. Journal of Adult Development, 23, 120-128. https://doi.org/10.1007 /s10804-016-9228-7.

Mangoulia, P., Koukia, E., Alevizopoulos, G., Fildissis, G., \& Katostaras, T. (2015). Prevalence of secondary traumatic stress among psychiatric nurses in Greece. Archives of Psychiatric Nursing, 29, 333-338. https://doi.org/10.1016/j.apnu.2015.06.001.

Manning-Jones, S., de Terte, I., \& Stephens, C. (2016). Secondary traumatic stress, vicarious posttraumatic growth, and coping among health professionals; a comparison study. New Zealand Journal of Psychology, $45,20-29$

Maslach, C. (1982). Burnout: The cost of caring. New York: Prentice-Hall.

Maslach, C. (1998). A multidimensional theory of burnout. In C. L. Cooper (Ed.), Theories of organizational stress (pp. 68-85). Oxford: Oxford University Press.

Maslach, C., Jackson, S. E., \& Leiter, M. P. (1996). The Maslach burnout inventory (3rd ed.). Palo Alto: Consulting Psychologists Press.

Maslach, C., Schaufeli, W. B., \& Leiter, M. P. (2001). Job burnout. Annual Review of Psychology, 52, 397422. https://doi.org/10.1146/annurev.psych.52.1.397.

McArthur, M. L., Andrews, J. R., Brand, C., \& Hazel, S. J. (2017). The prevalence of compassion fatigue among veterinary students in Australia and the associated psychological factors. Journal of Veterinary Medical Education, 44, 9-21. https://doi.org/10.3138/jvme.0116-016R3.

McCann, I. L., \& Pearlman, L. A. (1990). Vicarious traumatization: a framework for understanding the psychological effects of working with victims. Journal of Traumatic Stress, 3, 131-149. https://doi. org/10.1002/jts.2490030110. 
McClenahan, C. A., Giles, M. L., \& Mallett, J. (2007). The importance of context specificity in work stress research: a test of the demand-control-support model in academics. Work \& Stress, 21, 85-95. https://doi. org/10.1080/02678370701264552.

Meadors, P., Lamson, A., Swanson, M., White, M., \& Sira, N. (2009). Secondary traumatization in pediatric healthcare providers: compassion fatigue, burnout, and secondary traumatic stress. OMEGA-Journal of Death and Dying, 60, 103-128. https://doi.org/10.2190/OM.60.2.a.

Medvedev, O. N., Krägeloh, C. U., Narayanan, A., \& Siegert, R. J. (2017). Measuring mindfulness: applying generalizability theory to distinguish between state and trait. Mindfulness, 8, 1036-1046. https://doi. org/10.1007/s12671-017-0679-0.

Meehl, P. E. (1970). Nuisance variables and the ex post facto design. In M. Radner \& S. Winokur (Eds.), Minnesota Studies in the philosophy of science: Vol. IV. Analyses of theories and methods of physics and psychology (pp. 373-402). Minneapolis: University of Minnesota Press.

Meyer, R. M., Li, A., Klaristenfeld, J., \& Gold, J. I. (2015). Pediatric novice nurses: examining compassion fatigue as a mediator between stress exposure and compassion satisfaction, burnout, and job satisfaction. Journal of Pediatric Nursing: Nursing Care of Children and Families, 30, 174-183. https://doi. org/10.1016/j.pedn.2013.12.008.

Mizuno, M., Kinefuchi, E., Kimura, R., \& Tsuda, A. (2013). Professional quality of life of Japanese nurses/ midwives providing abortion/childbirth care. Nursing Ethics, 20, 539-550. https://doi.org/10.1177 /0969733012463723.

Molnar, B. E., Sprang, G., Killian, K. D., Gottfried, R., Emery, V., \& Bride, B. E. (2017). Advancing science and practice for vicarious traumatization/secondary traumatic stress: a research agenda. Traumatology, 23, 129-142. https://doi.org/10.1037/trm0000122.

Muliira, R. S., \& Ssendikadiwa, V. B. (2016). Professional quality of life and associated factors among Ugandan midwives working in Mubende and Mityana rural districts. Maternal and Child Health Journal, 20, 567-576. https://doi.org/10.1007/s10995-015-1855-2.

Munger, T., Savage, T., \& Panosky, D. M. (2015). When caring for perpetrators becomes a sentence: recognizing vicarious trauma. Journal of Correctional Health Care, 21, 365-374. https://doi. org/10.1177/1078345815599976.

Musa, S. A., \& Hamid, A. A. R. M. (2008). Psychological problems among aid workers operating in Darfur. Social Behavior and Personality, 36, 407-416. https://doi.org/10.2224/sbp.2008.36.3.407.

Nayani, R. J., Nielsen, K., Daniels, K., Donaldson-Feilder, E. J., \& Lewis, R. C. (2017). Out of sight and out of mind? A literature review of occupational safety and health leadership and management of distributed workers. Work \& Stress, 32, 124-146. https://doi.org/10.1080/02678373.2017.1390797.

Nesselroade, J. R. (1991). The warp and woof of the developmental fabric. In R. Downs, L. Liben, \& D. Palermo (Eds.), Visions of development, the environment, and aesthetics: The legacy of Joachim F. Wohlwill (pp. 213-240). Hillsdale: Erlbaum.

Newell, J. M., \& MacNeil, G. A. (2010). Professional burnout, vicarious trauma, secondary traumatic stress, and compassion fatigue: a review of theoretical terms, risk factors, and preventive methods for clinicians and researchers. Best Practices in Mental Health, 6, 57-68.

Newell, J. M., \& MacNeil, G. A. (2011). A comparative analysis of burnout and professional quality of life in clinical mental health providers and health care administrators. Journal of Workplace Behavioral Health, 26, 25-43. https://doi.org/10.1080/15555240.2011.540978.

Newell, J. M., Nelson-Gardell, D., \& MacNeil, G. (2016). Clinician responses to client traumas: a chronological review of constructs and terminology. Trauma, Violence, \& Abuse, 17, 306-313. https://doi. org/10.1177/1524838015584365.

Ng, E. C. W., Chan, S. M. P., \& Hui, H. (2012). Personnel psychology for disaster response and recovery. In S. C. Carr, A. Furnham, \& M. MacLachlan (Eds.), Humanitarian work psychology (pp. 225-246). https://doi.org/10.1057/9781137015228_10.

Nijp, H. H., Beckers, D. G. J., van de Voorde, K., Guerts, S. A. E., \& Kompier, M. A. J. (2016). Effects of new ways of working on work hours and work location, health and job-related outcomes. Chronobiology International, 33, 604-618. https://doi.org/10.3109/07420528.2016.1167731.

Nilsson, S., Sjöberg, M., Kallenberg, K., \& Larsson, G. (2011). Moral stress in international humanitarian aid and rescue operations: a grounded theory study. Ethics \& Behavior, 21, 49-68. https://doi.org/10.1080 $/ 10508422.2011 .537570$.

Noullet, C. J., Lating, J. M., Kirkhart, M. W., Dewey, R., \& Everly, G. S., Jr. (2018). Effect of pastoral crisis intervention training on resilience and compassion fatigue in clergy: a pilot study. Spirituality in Clinical Practice, 5, 1-7. https://doi.org/10.1037/scp0000158.

Novoa, M. P., \& Cain, D. S. (2014). The effects of reiki treatment on mental health professionals at risk for secondary traumatic stress. Best Practices in Mental Health, 10, 29-46. 
O'Brien, J. L., \& Haaga, D. A. F. (2015). Empathic accuracy and compassion fatigue among therapist trainees. Professional Psychology: Research and Practice, 46, 414 420. https://doi.org/10.1037/pro0000037.

O'Mahony, S., Ziadni, M., Hoerger, M., Levine, S., Baron, A., \& Gerhart, J. (2018). Compassion fatigue among palliative care clinicians: findings on personality factors and years of service. American Journal of Hospice \& Palliative Medicine, 35, 343-347. https://doi.org/10.1177/1049909117701695.

Onwuegbuzie, A. J. (2003). Effect sizes in qualitative research: a prolegomenon. Quality \& Quantity, 37, 393409. https://doi.org/10.1023/A:1027379223537.

Orkibi, H. (2016). Highly artistic-social personalities buffer the effects of burnout on career commitment. The Arts in Psychotherapy, 50, 75-83. https://doi.org/10.1016/j.aip.2016.06.006.

Pack, M. (2014). Vicarious resilience: a multilayered model of stress and trauma. Affilia: Journal of Women \& Social Work, 29, 18-29. https://doi.org/10.1177/0886109913510088.

Palestini, L., Prati, G., Pietrantoni, L., \& Cicognani, E. (2009). The professional quality of life in accident and emergency work: a contribution to the Italian validation of the Professional Quality of Life Scale (ProQOL). Italian Journal of Cognitive and Behavioural Psychotherapy, 15, 205-227.

Pearlman, L. A., \& Saakvitne, K. (1995). Trauma and the therapist: Countertransference and vicarious traumatization in psychotherapy with incest survivors. New York: W.W. Norton.

Pfaff, K. A., Freeman-Gibb, L., Patrick, L. J., DiBiase, R., \& Moretti, O. (2017). Reducing the "cost of caring" in cancer care: evaluation of a pilot interprofessional compassion fatigue resiliency programme. Journal of Interprofessional Care, 31, 512-519. https://doi.org/10.1080/13561820.2017.1309364.

Podsakoff, P. M., MacKenzie, S. B., Lee, J. Y., \& Podsakoff, N. P. (2003). Common method biases in behavioral research: a critical review of the literature and recommended remedies. Journal of Applied Psychology, 88, 879-903. https://doi.org/10.1037/0021-9010.88.5.879.

Podsakoff, N. P., LePine, J. A., \& LePine, M. A. (2007). Differential challenge stressor-hindrance stressor relationships with job attitudes, turnover intentions, turnover, and withdrawal behavior: a meta-analysis. Journal of Applied Psychology, 92, 438-454. https://doi.org/10.1037/0021-9010.92.2.438.

Potter, P., Deshields, T., Berger, J. A., Clarke, M., Olsen, S., \& Chen, L. (2013). Evaluation of a compassion fatigue resiliency program for oncology nurses. Oncology Nursing Forum, 40, 180-187. https://doi. org/10.1188/13.onf.180-187.

Prati, G., Pietrantoni, L., \& Cicognani, E. (2011). Coping strategies and collective efficacy as mediators between stress appraisal and quality of life among rescue workers. International Journal of Stress Management, 18, 181-195. https://doi.org/10.1037/a0021298.

Pross, C., \& Schweitzer, S. (2010). The culture of organizations dealing with trauma: sources of work-related stress and conflict. Traumatology, 16, 97-108. https://doi.org/10.1177/1534765610388301.

Quick, J. C., \& McFadyen, M. (2017). Sexual harassment: have we made any progress? Journal of Occupational Health Psychology, 22, 286-298. https://doi.org/10.1037/ocp0000054.

Rank, M. G., Zaparanick, T. L., \& Gentry, J. E. (2009). Nonhuman-animal care compassion fatigue: training as treatment. Best Practices in Mental Health, 5, 40-61.

Ravi, R., Yerraguntla, K., Gunjawate, D. R., Guddatthu, V., \& Bellur, R. (2016). Professional quality of life in audiologists and speech language pathologists working in India. Journal of Workplace Behavioral Health, 31, 162-172. https://doi.org/10.1080/15555240.2016.1192475.

Ray, S. L., Wong, C., White, D., \& Heaslip, K. (2013). Compassion satisfaction, compassion fatigue, work life conditions, and burnout among frontline mental health care professionals. Traumatology, 19, 255-267. https://doi.org/10.1177/1534765612471144.

Riley, K. E., Park, C. L., Wilson, A., Sabo, A. N., Antoni, M. H., Braun, T. D., Harrington, J., et al. (2017). Improving physical and mental health in frontline mental health care providers: yoga-based stress management versus cognitive behavioral stress management. Journal of Workplace Behavioral Health, 32, 26-48. https://doi.org/10.1080/15555240.2016.1261254.

Robb, A. E., Due, C., \& Venning, A. (2016). Exploring psychological wellbeing in a sample of Australian actors. Australian Psychologist, 53, 77-86. https://doi.org/10.1111/ap.12221.

Robertson, I. T., Cooper, C. L., Sarkar, M., \& Curran, T. (2015). Resilience training in the workplace from 2003 to 2014: a systematic review. Journal of Occupational and Organizational Psychology, 88, 533562. https://doi.org/10.1111/joop.12120.

Robinson-Keilig, R. A. (2014). Secondary traumatic stress and disruptions to interpersonal functioning among mental health therapists. Journal of Interpersonal Violence, 29, 1477-1496. https://doi.org/10.1177 $/ 0886260513507135$.

Roney, L. N., \& Acri, M. C. (2018). The cost of caring: an exploration of compassion fatigue, compassion satisfaction, and job satisfaction in pediatric nurses. Journal of Pediatric Nursing, 40, 74-80. https://doi. org/10.1016/j.pedn.2018.01.016. 
Rosenthal, R. (1995). Writing meta-analytic reviews. Psychological Bulletin, 118, 183-192. https://doi. org/10.1037/0033-2909.118.2.183.

Rossi, A., Cetrano, G., Pertile, R., Rabbi, L., Donisi, V., Grigoletti, L., et al. (2012). Burnout, compassion fatigue, and compassion satisfaction among staff in community-based mental health services. Psychiatry Research, 200, 933-938. https://doi.org/10.1016/j.psychres.2012.07.029.

Ruysschaert, N. (2009). (Self) hypnosis in the prevention of burnout and compassion fatigue for caregivers: theory and induction. Contemporary Hypnosis, 26, 159-172. https://doi.org/10.1002/ch.382.

Sabin-Farrell, R., \& Turpin, G. (2003). Vicarious traumatization: implications for the mental health of health workers? Clinical Psychology Review, 23, 449-480. https://doi.org/10.1016/s0272-7358(03)00030-8.

Sabo, B. M. (2006). Compassion fatigue and nursing work: can we accurately capture the consequences of caring work? International Journal of Nursing Practice, 12, 136-142. https://doi.org/10.1111/j.1440-172 X.2006.00562.x.

Samios, C., Abel, L. M., \& Rodzik, A. K. (2013). The protective role of compassion satisfaction for therapists who work with sexual violence survivors: an application of the broaden-and-build theory of positive emotions. Anxiety, Stress, \& Coping, 26, 610-623. https://doi.org/10.1080/10615806.2013.784278.

Samson, T., Iecovich, E., \& Shvartzman, P. (2016). Psychometric characteristics of the Hebrew version of the professional quality-of-life scale. Journal of Pain and Symptom Management, 52, 575-581. https://doi. org/10.1016/j.jpainsymman.2016.03.019.

Sandelowski, M. (1993). Rigor or rigor mortis: the problem of rigor in qualitative research revisited. Advances in Nursing Science, 16, 1-8. https://doi.org/10.1097/00012272-199312000-00002.

Sawatzky, J.-A. V., \& Enns, C. L. (2012). Exploring the key predictors of retention in emergency nurses. Journal of Nursing Management, 20, 696-707. https://doi.org/10.1111/j.1365-2834.2012.01355.x.

Schabram, K., \& Maitlis, S. (2017). Negotiating the challenges of a calling: emotion and enacted sensemaking in animal shelter work. Academy of Management Journal, 60, 584-609. https://doi.org/10.5465 /amj.2013.0665.

Selye, H. (1974). Stress sans détresse. Philadelphia: Lippincott.

Semmer, N. K., Grebner, S., \& Elfering, A. (2003). Beyond self-report: Using observational, physiological, and situation-based measures in research on occupational stress. In P. L. Perrewé \& D. C. Ganster (Eds.), Emotional and physiological processes and positive intervention strategies (pp. 205-263). https://doi. org/10.1016/s1479-3555(03)03006-3.

Setti, I., \& Argentero, P. (2014). The role of mindfulness in protecting firefighters from psychosomatic malaise. Traumatology, 20, 134-141. https://doi.org/10.1037/h0099398.

Setti, I., Lourel, M., \& Argentero, P. (2016). The role of affective commitment and perceived social support in protecting emergency workers against burnout and vicarious traumatization. Traumatology, 22, 261-270. https://doi.org/10.1037/trm0000072.

Shah, S. A., Garland, E., \& Katz, C. (2007). Secondary traumatic stress: prevalence in humanitarian aid workers in India. Traumatology, 13, 59-70. https://doi.org/10.1177/1534765607299910.

Shoji, K., Bock, J., Cieslak, R., Zukowska, K., Luszczynska, A., \& Benight, C. C. (2014). Cultivating secondary traumatic growth among healthcare workers: the role of social support and self-efficacy. Journal of Clinical Psychology, 70, 831-846. https://doi.org/10.1002/jclp.22070.

Shoji, K., Lesnierowska, M., Smoktunowicz, E., Bock, J., Luszczynska, A., Benight, C. C., \& Cieslak, R. (2015). What comes first, job burnout or secondary traumatic stress? Findings from two longitudinal studies from the U.S. and Poland. PLoS One, 10, e0136730. https://doi.org/10.1371/journal. pone. 0136730 .

Silver, J., Caleshu, C., Casson-Parkin, S., \& Ormond, K. (2018). Mindfulness among genetic counselors is associated with increased empathy and work engagement and decreased burnout and compassion fatigue. Journal of Genetic Counseling. Advance online publication. https://doi.org/10.1007/s10897-018-0236-6.

Sinclair, S., Raffin-Bouchal, S., Venturato, L., Mijovic-Kondejewski, J., \& Smith-MacDonald, L. (2017). Compassion fatigue: a meta-narrative review of the healthcare literature. International Journal of Nursing Studies, 69, 9-24. https://doi.org/10.1016/j.ijnurstu.2017.01.003.

Singh, N. N., Lancioni, G. E., Medvedev, O. N., Myers, R. E., Chan, J., McPherson, C. L., ... Kim, E. (2018). Comparative effectiveness of caregiver training in mindfulness-based positive behavior support (MBPBS) and positive behavior support (PBS) in a randomized controlled trial. Mindfulness. Advance online publication. https://doi.org/10.1007/s12671-018-0895-2.

Slatten, L. A., Carson, D., \& Carson, P. P. (2011). Compassion fatigue and burnout: what managers should know. The Health Care Manager, 30, 325-333. https://doi.org/10.1097/hcm.0b013e31823511f7.

Slattery, S. M., \& Goodman, L. A. (2009). Secondary traumatic stress among domestic violence advocates: workplace risk and protective factors. Violence Against Women, 15, 1358-1379. https://doi.org/10.1177 /1077801209347469. 
Slatyer, S., Craigie, M., Heritage, B., Davis, S., \& Rees, C. (2018). Evaluating the effectiveness of a brief mindful self-care and resiliency (MSCR) intervention for nurses: a controlled trial. Mindfulness, 9, 534 546. https://doi.org/10.1007/s12671-017-0795-x.

Sonnentag, S., \& Binnewies, C. (2013). Daily affect spillover from work to home: detachment from work and sleep as moderators. Journal of Vocational Behavior, 83, 198-208. https://doi.org/10.1016/j. jvb.2013.03.008.

Sparks, K., \& Cooper, C. L. (1999). Occupational differences in the work-strain relationship: towards the use of situation-specific models. Journal of Occupational and Organizational Psychology, 72, 219-229. https://doi.org/10.1348/096317999166617.

Sprang, G., \& Craig, C. (2015). An inter-battery exploratory factor analysis of primary and secondary traumatic stress: determining a best practice approach to assessment. Best Practices in Mental Health, $11,1-13$.

Sprang, G., Ross, L., Miller, B. C., Blackshear, K., \& Ascienzo, S. (2017). Psychometric properties of the secondary traumatic stress-informed organizational assessment. Traumatology, 23, 165-171. https://doi. org/10.1037/trm0000108.

Stamm, B. H. (2010). The concise ProQOL manual (2nd ed.). Pocatello: ProQOL.org.

Stamm, B. H., Lambert, D., Piland, N. F., \& Speck, N. C. (2007). A rural perspective on health care for the whole person. Professional Psychology: Research and Practice, 38, 298-304. https://doi.org/10.1037 /0735-7028.38.3.298.

Stephens, J. P., Heaphy, E. D., Carmeli, A., Spreitzer, G. M., \& Dutton, J. E. (2013). Relationship quality and virtuousness; emotional carrying capacity as a source of individual and team resilience. The Journal of Applied Behavioral Science, 49, 13-41. https://doi.org/10.1177/0021886312471193.

Stevenson, A. D., Phillips, C. B., \& Anderson, K. J. (2011). Resilience among doctors who work in challenging areas: a qualitative study. British Journal of General Practice, 61, e404-e410. https://doi. org/10.3399/bjgp11X583182.

Stewart, D. W. (2012). Compassion fatigue: what is the level among army chaplains? Journal of Workplace Behavioral Health, 27, 1-11. https://doi.org/10.1080/15555240.2012.640574.

Stone-Romero, E. F., \& Rosopa, P. J. (2008). The relative validity of inferences about media as a function of research design characteristics. Organizational Research Methods, 11, 326-352. https://doi.org/10.1177 $/ 1094428107300342$.

Sung, K., Seo, Y., \& Kim, J. H. (2012). Relationships between compassion fatigue, burnout, and turnover intention in Korean hospital nurses. Journal of Korean Academy of Nursing, 42, 1087-1094. https://doi. org/10.4040/jkan.2012.42.7.1087.

Tabaj, A., Pastirk, S., Bitenc, C., \& Masten, R. (2015). Work-related stress, burnout, compassion, and work satisfaction of professional workers in vocational rehabilitation. Rehabilitation Counseling Bulletin, 58, 113-123. https://doi.org/10.1177/0034355214537383.

Tavormina, M., \& Clossey, L. (2017). Exploring crisis and its effects on workers in protective services work. Child \& Family Social Work, 22, 126-136. https://doi.org/10.1111/cfs.12209.

Thomas, J. T., \& Otis, M. D. (2010). Intrapsychic correlates of professional quality of life: mindfulness, empathy, and emotional separation. Journal of the Society for Social Work and Research, 1, 83-98. https://doi.org/10.5243/jsswr.2010.7.

Thompson, I., Amatea, E., \& Thompson, E. (2014). Personal and contextual predictors of mental health counselors' compassion fatigue and burnout. Journal of Mental Health Counseling, 36, 58-77. https://doi. org/10.17744/mehc.36.1.p61m73373m4617r3.

Ting, L., Jacobson, J. M., Sanders, S., Bride, B. E., \& Harrington, D. (2005). The secondary traumatic stress scale (STSS) confirmatory factor analyses with a national sample of mental health social workers. Journal of Human Behavior in the Social Environment, 11, 177-194. https://doi.org/10.1300/J137v11n03_09.

Ting, L., Jacobson, J. M., \& Sanders, S. (2008). Available supports and coping behaviors of mental health social workers following fatal and nonfatal client suicidal behavior. Social Work, 53, 211-221. https://doi. org/10.1093/sw/53.3.211.

Tosone, C., McTighe, J. P., Bauwens, J., \& Naturale, A. (2011). Shared traumatic stress and the long-term impact of 9/11 on Manhattan clinicians. Journal of Traumatic Stress, 24, 546-552. https://doi.org/10.1002 /jts.20686.

Townsend, S. M., \& Campbell, R. (2009). Organizational correlates of secondary traumatic stress and burnout among sexual assault nurse examiners. Journal of Forensic Nursing, 5, 97-106. https://doi.org/10.1111 j.1939-3938.2009.01040.x.

Truxillo, D. M., Cadiz, D. M., \& Hammer, L. B. (2015). Supporting the aging workforce: a review and recommendations for workplace intervention research. The Annual Review of Organizational Psychology and Organizational Behavior, 2, 351-381. https://doi.org/10.1146/annurev-orgpsych-032414-111435. 
Tucker, T., Bouvette, M., Daly, S., \& Grassau, P. (2017). Finding the sweet spot: developing, implementing and evaluating a burn out and compassion fatigue intervention for third year medical trainees. Evaluation and Program Planning, 65, 106-112. https://doi.org/10.1016/j.evalprogplan.2017.07.006.

Turgoose, D., \& Maddox, L. (2017). Predictors of compassion fatigue in mental health professionals: a narrative review. Traumatology, 23, 172-185. https://doi.org/10.1037/trm0000116.

Turliuc, M. N., Mairean, C., \& Turliuc, M. D. (2015). Rumination and suppression as mediators of the relationship between dysfunctional beliefs and traumatic stress. International Journal of Stress Management, 22, 306-322. https://doi.org/10.1037/a0039272.

Tyler, T. A. (2012). The limbic model of systemic trauma. Journal of Social Work Practice, 26, 125-138. https://doi.org/10.1080/02650533.2011.602474.

Van den Broeck, A., De Cuyper, N., De Witte, H., \& Vansteenkiste, M. (2010). Not all job demands are equal: differentiating job hindrances and job challenges in the job demands-resources model. European Journal of Work and Organizational Psychology, 19, 735-759. https://doi.org/10.1080/13594320903223839.

van der Ploeg, E., Dorresteijn, S. M., \& Kleber, R. J. (2003). Critical incidents and chronic stressors at work: their impact on forensic doctors. Journal of Occupational Health Psychology, 8, 157-166. https://doi. org/10.1037/1076-8998.8.2.157.

van der Watch, A., van Wyk, N., \& van Rensburg, E. J. (2013). Emergency nurses' experiences of caring for survivors of intimate partner violence. Journal of Advanced Nursing, 69, 2242-2252. https://doi. org/10.1111/jan.12099.

van Mol, M. M. C., Kompanje, E. J. O., Benoit, D. D., Bakker, J., \& Nijkamp, M. (2015). The prevalence of compassion fatigue and burnout among healthcare professionals in intensive care units: a systematic review. PLoS ONE, 10, e0136955. https://doi.org/10.1371/journal.pone.0136955.

Van Sant, J. E., \& Patterson, B. J. (2013). Getting in and getting out whole: nurse-patient connections in the psychiatric setting. Issues in Mental Health Nursing, 34, 36-45. https://doi.org/10.3109 /01612840.2012.715321.

Verhaeghe, S., Duprez, V., Beeckman, D., Leys, J., Van Meijel, B., \& Van Hecke, A. (2016). Mental health nurses' attitudes and perceived self-efficacy toward inpatient aggression: a cross-sectional study of associations with nurse-related characteristics. Perspectives in Psychiatric Care, 52, 12-24. https://doi. org/10.1111/ppc.12097.

Veronese, G., \& Pepe, A. (2017). Sense of coherence as a determinant of psychological well-being among professional groups of aid workers exposed to war trauma. Journal of Interpersonal Violence, 32, 18991920. https://doi.org/10.1177/0886260515590125.

Vio, C. G., \& Vidallet, J. L. S. (2007). Psychometric examination of the Secondary Traumatic Stress Scale: a study on Chileans professionals. Sicologia Conductual Revista Internacional de Psicologia Clinica de la Salud, 15, 441-456.

Vrklevsiki, L. P., \& Franklin, J. (2008). Vicarious trauma: the impact on solicitors of exposure to traumatic material. Traumatology, 14, 106-118. https://doi.org/10.1177/1534765607309961.

Wald, H. S., Haramati, A., Bachner, Y. G., \& Urkin, J. (2016). Promoting resiliency for interprofessional faculty and senior medical students: outcomes of a workshop using mind-body medicine and interactive reflective writing. Medical Teacher, 38, 525-528. https://doi.org/10.3109/0142159X.2016.1150980.

Weidlich, C. P., \& Ugarriza, D. N. (2015). A pilot study examining the impact of care provider support program on resiliency, coping, and compassion fatigue in military health care providers. Military Medicine, 180, 290-295. https://doi.org/10.7205/milmed-d-14-00216.

West, A. L. (2015). Associations among attachment style, burnout, and compassion fatigue in health and human service workers: a systematic review. Journal of Human Behavior in the Social Environment, 25, 571-590. https://doi.org/10.1080/10911359.2014.988321.

Wheeler, M. S., Arnkoff, D. B., \& Glass, C. R. (2017). The neuroscience of mindfulness: how mindfulness alters the brain and facilitates emotion regulation. Mindfulness, 8, 1471-1487. https://doi.org/10.1007 /s12671-017-0742-x.

Whitebird, R. R., Asche, S. E., Thompson, G. L., Rossom, R., \& Heinrich, R. (2013). Stress, burnout, compassion fatigue, and mental health in hospice workers in Minnesota. Journal of Palliative Medicine, 16, 1534-1539. https://doi.org/10.1089/jpm.2013.0202.

Williams, A. M., Helm, H. M., \& Clemens, E. V. (2012). The effect of childhood trauma, personal wellness, supervisory working alliance, and organizational factors on vicarious traumatization. Journal of Mental Health Counseling, 34, 133-153. https://doi.org/10.17744/mehc.34.2.j3162k872325h583.

Wood, A. E., Prins, A., Bush, N. E., Hsia, J. F., Bourn, L. E., Earley, M. D., et al. (2017). Reduction of burnout in mental health care providers using the provider resilience mobile application. Community Mental Health Journal, 53, 452-459. https://doi.org/10.1007/s10597-016-0076-5. 
Wylde, C. M., Mahrer, N. E., Meyer, R. M., \& Gold, J. I. (2017). Mindfulness for novice pediatric nurses: smartphone application versus traditional intervention. Journal of Pediatric Nursing, 36, 205-212. https://doi.org/10.1016/j.pedn.2017.06.008.

Yan, G. W., \& Beder, J. (2013). Professional quality of life and associated factors among VHA chaplains. Military Medicine, 178, 638-645. https://doi.org/10.7205/milmed-d-13-00021.

Yeung, P., White, B., \& Chilvers, B. L. (2017). Exploring wellness of wildlife carers in New Zealand: a descriptive study. Anthrozoös, 30, 549-563. https://doi.org/10.1080/08927936.2017.1370213.

Yip, S. Y., Mak, W. W., Chio, F. H., \& Law, R. W. (2017). The mediating role of self-compassion between mindfulness and compassion fatigue among therapists in Hong Kong. Mindfulness, 8, 460-470. https://doi.org/10.1007/s12671-016-0618-5.

Yu, H., Jiang, A., \& Shen, J. (2016). Prevalence and predictors of compassion fatigue, burnout and compassion satisfaction among oncology nurses: a cross-sectional survey. International Journal of Nursing Studies, 57, 28-38. https://doi.org/10.1016/j.ijnurstu.2016.01.012.

Zadeh, S., Gamba, N., Hudson, C., \& Wiener, L. (2012). Taking care of care providers: a wellness program for pediatric nurses. Journal of Pediatric Oncology Nursing, 29, 294-299. https://doi.org/10.1177 /1043454212451793.

Zeleskov-Doric, J., Hedrih, V., \& Doric, P. (2012). Relations of resilience and personal meaning with vicarious traumatization in psychotherapists. International Journal of Psychotherapy, 16, 44-55.

Publisher's Note Springer Nature remains neutral with regard to jurisdictional claims in published maps and institutional affiliations. 